University of Rhode Island

DigitalCommons@URI

Open Access Master's Theses

1987

\title{
Gas Chromatographic/Infared Spectral Analysis Using a Computer Integrated Circular Variable Filter Spectrometer
}

Mark Ahmadjian

University of Rhode Island

Follow this and additional works at: https://digitalcommons.uri.edu/theses

\section{Recommended Citation}

Ahmadjian, Mark, "Gas Chromatographic/Infared Spectral Analysis Using a Computer Integrated Circular Variable Filter Spectrometer" (1987). Open Access Master's Theses. Paper 943.

https://digitalcommons.uri.edu/theses/943

This Thesis is brought to you for free and open access by DigitalCommons@URI. It has been accepted for inclusion in Open Access Master's Theses by an authorized administrator of DigitalCommons@URI. For more information, please contact digitalcommons-group@uri.edu. 
GAS CHROMATOGRAPHIC/INFRARED SPECTRAL ANALYSIS USING A COMPUTER INTERFACED CIRCULAR VARIABLE FILTER SPECTROMETER

BY

MARK AHMADJIAN

A THESIS SUBMITTED IN PARTIAL FULFILLMENT OF THE REQUIREMENTS FOR THE DEGREE OF

MASTER OF SCIENCE

IN

CHEMISTRY

UNIVERSITY OF RHODE ISLAND

1987 
MASTER OF SCIENCE THESIS

OF

MARK AHMADJIAN

APPROVED :

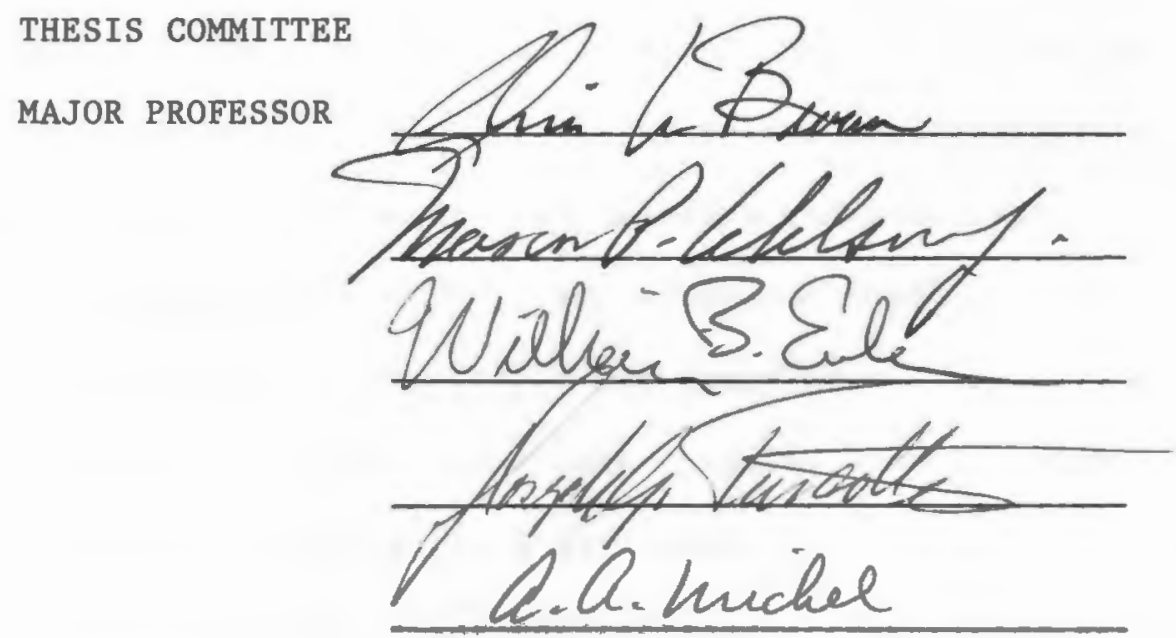

DEAN OF THE GRADUATE SCHOOL 


\section{ABSTRACT}

Gas chromatography/infrared spectroscopy (GC/IR) is a powerful analytical technique for "on-the-fly" analysis of multi-component mixtures. The gas chromatograph separates the mixture into single components which are then analyzed by the spectrometer as they elute off the gc column and into the spectrometer. Standard instrumention usually involves a gas chomatograph, a fourier transform infrared spectrometer (FT-IR), and a computer system. The end products are a reconstructed gas chromatogram and a number of infrared spectra for each of the mixture components. These pieces of information often allow the identification of an unknown mixture. A GC/FT-IR/Computer System, however, is an elaborate and expensive laboratory instrument which requires extensive care, maintenance, and a well trained operator. It is not designed for field use and is seldom deployed outside of a laboratory. The objective of this research therefore was to develop a simple and inexpensive GC/IR/Computer System which would be rugged, easy to use, and readily adaptable for field use.

To do this, we interfaced a fast scanning circular variable filter (CVF) infrared spectrometer to a mini-computer and then coupled the spectrometer/computer to a gas chromatograph. The system was configured such that the same end products generated by a GC/FT-IR/Computer System, i.e. reconstructed gas chromatograms and infrared spectra, are also generated by this GC/CVF-IR/ Computer System. A five component mixture of hazardous class type compounds with closely related boiling points was analyzed to demonstrate the feasibility of this new system. 


\section{ACKNOWLEDGEMENTS}

I would like to thank my major professor, Dr. Chris W. Brown, for his guidance, teaching, and most of all his friendship throughout the years.

My thanks to the U.S. Air Force for providing me with the opportunity to finish this degree and special thanks to Dr. Randall E. Murphy, Director, Infrared Technology Division, AF Geophysics Laboratory, for his support and encouragement. /

Mark Ahmadjian 


\section{PREFACE}

This thesis was prepared in accordance with the standard thesis plan. 
TABLE OF CONTENTS

$\underline{\text { Page }}$

ABSTRACT $\ldots \ldots \ldots \ldots \ldots \ldots \ldots \ldots \ldots \ldots \ldots \ldots \ldots \ldots \ldots \ldots \ldots \ldots \ldots \ldots$

ACKNOWLEDGEMENT............................... 111

PREFACE.................................... 1v

LIST OF FIGURES............................... vi

INTRODUCTION................................ 1

HISTORY.................................... 2

EXPERIMENTAL SECTION............................. 3

RESULTS AND DISCUSSION.......................... 9

ConCLUSION...................................... 25

REFERENCES.................................... 27

BIBLIOGRAPHY................................ 28

APPENDIX.................................... 30 
1. Block diagram of the GC/IR computer system....... 4

2. Beckman IR-102 optical diagram............. 5

3. Sequence of events for the GC/IR computer analysis.. 7

4. TWIRP (Total Wavelength IR Plot) A reconstructed gas chromatogram........................ 12

5. Spectral plots corresponding to the TWIRP peak in

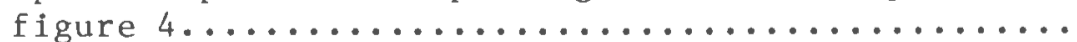

6. TWIRP for a five component mixture consisting of (1) methanol (2) acetone, (3) chloroform, (4) carbon tetrachloride, and (5) benzene in a carbon disulfide solution $\left(\mathrm{CS}_{2}\right.$ vented to atmosphere).......

7. Infrared spectra for the five component mixture corresponding to the TWIRP peak in figure 6 . Scan \#l 1 is the instrument background while scans 14,22 , 41,47 , and 55 correspond to the TWIRP peaks $k_{1} 1$, 非,

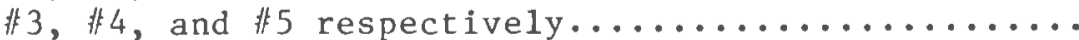

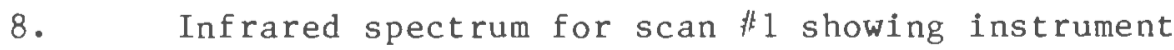
background. Absorptions are due to ambient $\mathrm{CO}_{2}$ and

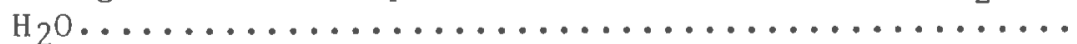

9. Infrared spectrum for scan \#14 which corresponds to the first TWIRP peak of figure 6 and is due to

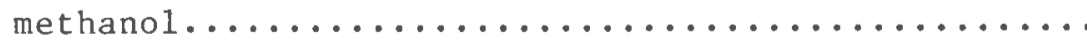

10. Infrared spectrum for scan \#22 which corresponds to the second TWIRP peak of figure 6 and is due to

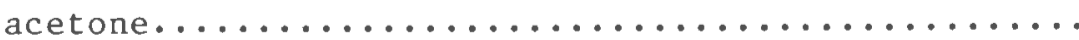

11. Infrared spectrum for scan \#41 which corresponds to the third TWIRP peak of figure 6 and is due to

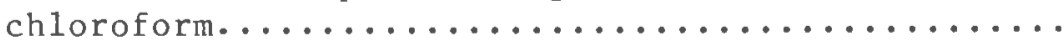

12. Infrared spectrum for scan $\#_{44}$ which corresponds to the fourth TWIRP peak of figure 6 and is due to

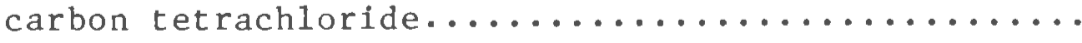




\section{LIST OF FIGURES}

Figure

13. Infrared spectrum for scan 非5 which corresponds to the fifth TWIRP peak of figure 6 and is due to

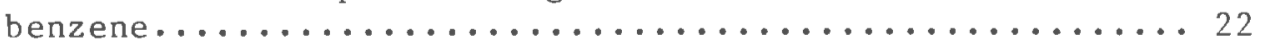

14. Comparision of a gas chromatogram (flame ionization detector) to the TWIRP reconstructed gas chromatogram of a five component mixture of methanol, acetone, chloroform, carbon tetrachloride, and benzene......... 24

15. Computer processing of Beckman IR-102 spectra demonstrating signal averaging and smoothing techniques.. 26 


\section{INTRODUCTION}

Since the 1950s infrared spectroscopy has been used to identify components separated by gas chromatography. Early efforts $1-10$ involved grating or prism type spectrometers which, however, lacked the wavelength scanning speed to adequately measure chemical compounds eluting from gas chromatographs in real time, 1.e. on-the-fly. It was usually necessary to trap the components and hold them in a trap or matrix unt 11 an infrared spectrum of the sample was obtalned. This was time consuming and did not provide for generation of reconstucted gas chromatograms. Not unt11 Cooley and Tukey (11) developed their algor thm for fast processing of interferograms and the ready avallablity of laboratory computers did actual GC/IR "on-the-fly" analysis become practical. For the first time a gas chromatograph could be coupled directly to a Fourier Transform - Infrared instrument (FT-IR) for analysis of multi-component mixtures with results plotted out by computer in the form of reconstructed gas chromatograms with corresponding spectra for the Individual gas chromatographic peaks. The ability of the FT-IR system to rapidly acquire interferograms over a broad spectral region revolutionized the analysis of mixtures by gas chromatography. Today there are a number of GC/FT-IR instruments available (Nicolet, Perkin-Elmer, Digilab, IBM, and others); however, they are expensive, complicated (moving mirrors, air bearings, lasers, extensive data processing requirements), and are found only in a limited number of laboratories. In addition, they are not considered to be field type instruments. The objective of this research was to 
develop a simple, inexpensive, and transportable GC/IR system using a circular variable filter (CVF) infrared spectrometer controlled by a small mini-computer. This combination could provide facilities with an inexpensive and easy to use survey type instrument for fast characterization of multi-component mixtures.

To do this we used a Beckman IR-102 fast scanning CVF Infrared spectrometer to measure gas chromatographic effluents by passing the volatile fractions through a gold plated light pipe in the optical path of the spectrometer while it scanned the $2.5-14.5$ um region.

\section{History}

Analysis of gas chromatographic fraction with an IR-102 is not new. Beckman Instruments developed this instrument in 1965 for this purpose 12 At that time though there were few laboratory computers in routine use and spectra were recorded by a fast oscillographic recorder which necessitated manually and 1aboriously examining many feet of heat sensitive chart paper to pick out the infrared spectrum of interest. Needless to say this technique was not accepted by the analytical community and only a few IR-102's were ever sold. There is no evidence at Beckman Instruments or in the 11terature that this type of fast scanning CVF spectrometer was ever interfaced to a computer to perform the same tasks as a GC/FT-IR (however, the U.S. Air Force did use computerized CVF spectrometers for chemical analysis of the earth's upper atmosphere from sounding rockets and high altitude balloons). 
Th1s paper w111 show how a GC/IR-102 can be Interfaced to a Data) General Corporation NOVA $3 / 12 \mathrm{minl}$-computer and developed the software to perform GC/IR analysis on-the-fly. The system is demonstrated on a one component solution and then on a five component mixture of closely bolling compounds; acetone b.p. $56 \mathrm{C}$, chloroform b.p. $61 \mathrm{C}$, methanol b.p. 64 C, carbon tetrachlor1de b.p. 76 C, and benzene b.p. 80 C. The GC/IR not only provides a reconstructed gas chromatogram comparable to standard flame ionization detection (FID) gas chromatograms but, also generates infrared spectra for each of the chromatographic peaks.

\section{EXPERIMENTAL SECTION}

\section{Instrumentation}

Figure 1 is a block diagram of the GC/IR computer system. A HP-7100 gas chromatograph with a Supelco $10 \%$ SP-2250, $100 / 120$ Supelcoport, $1 / 8^{\prime \prime} \times 10^{\prime}$ column was directly coupled to the Beckman IR-102 gold plated $10 \mathrm{~cm}$ long 11ght plpe. The 1nterface 11 ne was heated to $150^{\circ} \mathrm{C}$ and was thermostatically controlled. $100 \%$ of the $g \cdot c$. effluent was allowed to pass through the sample cell. The flow rate was varled from $10-15 \mathrm{cc} / \mathrm{m}$ nute. The optical path and components of the IR-102 were used as designed except it was no longer necessary to use the trap and hold option valves for the sample cell. Figure 2 shows the optlcal layout. A Nernst glower was used as the IR source and chopped at $120 \mathrm{~Hz}$. The beam Is directed through the heated sample cell. A torroldal mirror collected the radiation and reflected it onto a flat mirror and through the CVF wheel, 


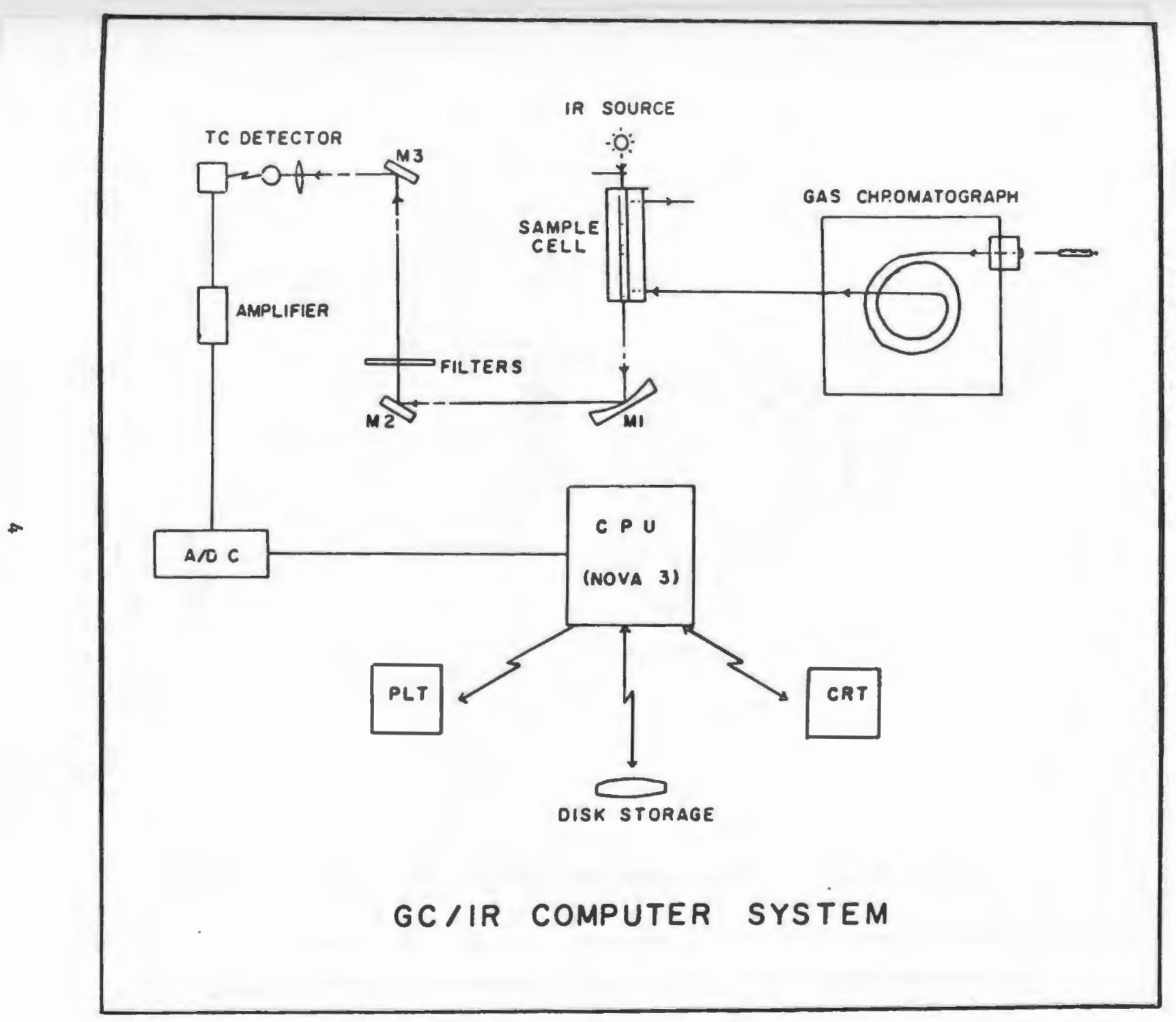

Figure 1. Block dlagram of the GC/IR computer systen 


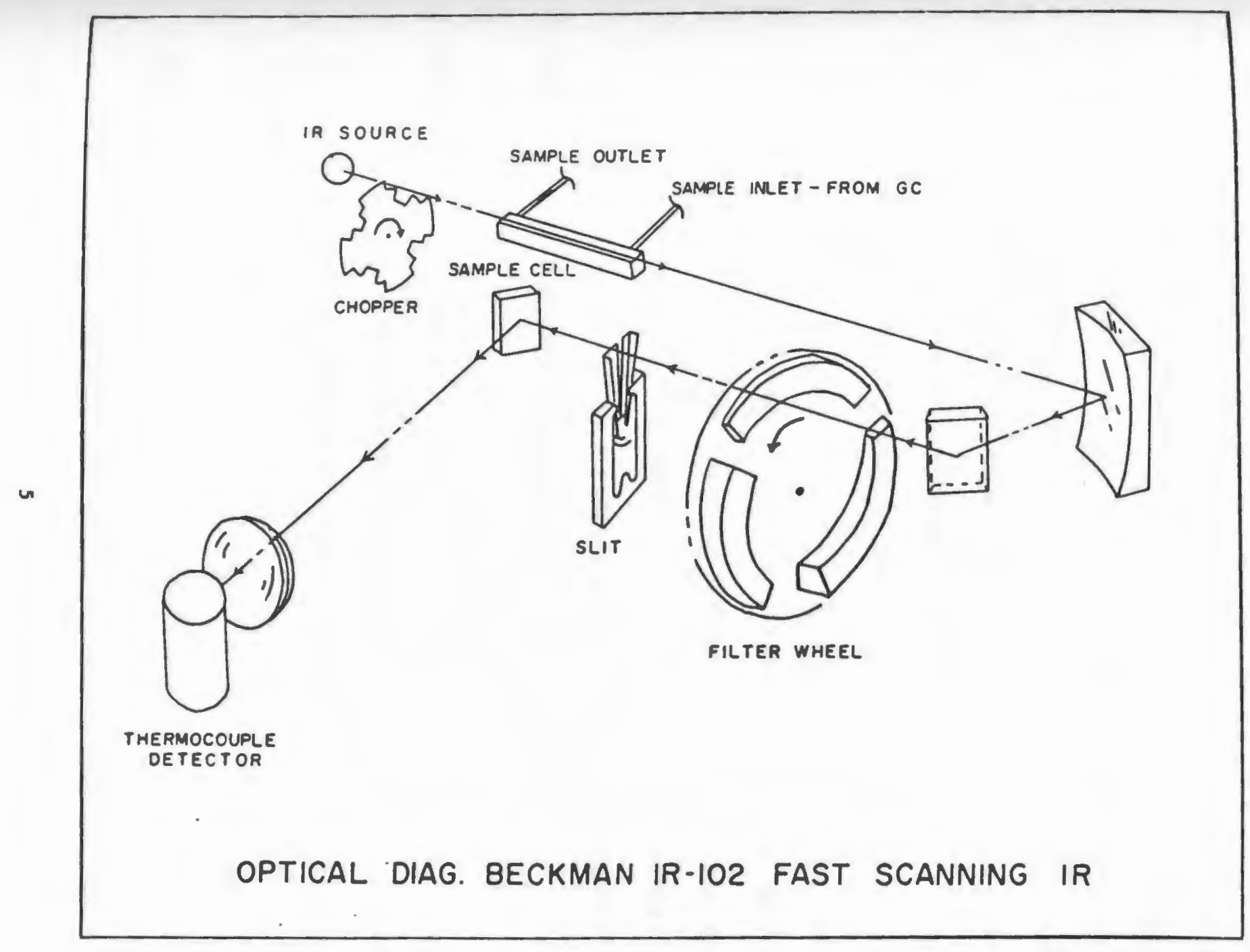

Flgure 2. Beckman IR-102 optlcal diagran (redrawn from Beckman user's manual) 
a slit, and onto a thermocouple detector. The filter wheel consists of three wedge shaped segments covering the infrared wavelength range of $2.5-4.5 \mathrm{um}, 4.4-8.0 \mathrm{um}$, and $7.9-14.5 \mathrm{um}$. The analog output signal from the detector is passed through a signal conditioning channel where it is inverted and amplified to 0 to $+10 \mathrm{VDC}$. The signal is then sampled by the DGC NOVA $3 / 1216$ bit analog digital converter. The sampling rate is determined by an internal oscillator, $1000 \mathrm{~Hz}$ clock, under software control. The digitized signal is then stored in contiguous data blocks on a 5 Megabit cartridge disk subsequent to any additional processing. The data can then be processed and displayed in a variety of ways. Usually a Total Wavelength IR Plot (TWIRP), i.e. the reconstructed gas chromatogram, is first generated to show how many components were in the mixture. The individual spectra for each of the reconstructed g.c. peaks can then be displayed as a function of scan number. The spectra can also be slgnal averaged, smoothed, and subtracted. Figure 3 shows a typlcal sequence of events for this analysis.

\section{Samples}

Mixtures were prepared by mixing equal volumes of reagent grade acetone, chloroform, methanol, carbon tetrachloride, and benzene in carbon disulfide.

\section{Sof tware}

Eight computer programs were written for this system. By using 


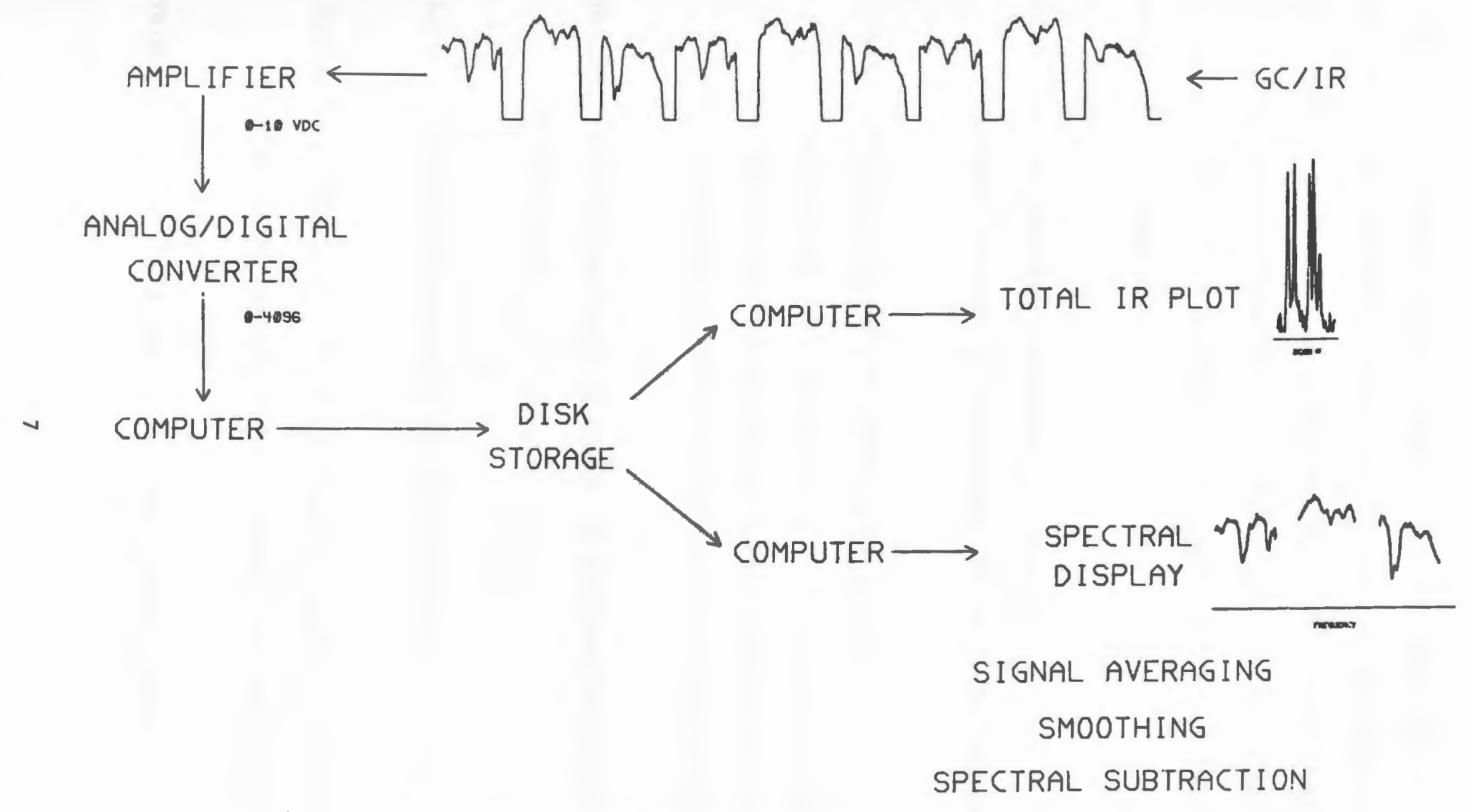

Figure 3. Sequence of events for the GC/IR computer analysis 
Individual programs we were able to develop, test, and debug the hardware/software one phase at a time. The individual programs are brought into memory by a maln controller program. When not in use, they reside in one of the user directorles on disk. The following is a 11st of the programs with a brief description of each. Coples of the programs are attached as an appendix.

GCIR: This is the main controller program, the executive, and allows the other programs to be brought into use via swap commands.

GCIRAD: Th1s program and 1ts subroutines samples the IR-102 analog detector signal through a multiplexer, performs an analog to digital conversion via the analog digital converter ( $A D C)$, and stores the digitized data into an optimally sized contiguous data file on disk.

GCIRSUB: A subroutine used by GCIRAD to inftiate data acquisition and store data on disk.

ADGCIR: An assembly language subroutine to sample the ADC.

GCIRCAL: Calibrates all the Individually acquired IR spectra using the 0 VDC signal between filter elements one and three.

TWIRP: Plots out the reconstructed gas chromatograms. 
GCIRSPEC: Plots out individual spectra corresponding to peaks from the recontructed gas chromatograms.

GCIRSUM: Signal averages any number of IR spectra.

\section{RESULTS AND DISCUSSION}

We want to show that this GC/IR system using a computer interfaced IR-102 infrared circular variable f1lter spectrometer is able to analyze a multi-component mixture in a manner similar to that of a sophisticated GC/FT-IR/computer system. As in any research endeavor, we started off with a simple feasibility demonstration which involved the measurement of a one component mixture. In this case we used acetone in carbon disulfide. Carbon disulfide was chosen as the solvent because our laboratory was using 1 t on a routine basis for IR analysis of hydrocarbon solutions and because carbon disulfide has a large IR "window" and would therefore present minimal spectral interferences for low bolling compounds. To prevent gross $\mathrm{CS}_{2}$ contamination of the gold plated IR sample cell, the solvent peak was vented via a bypass valve to an exhaust hood. Once the $\mathrm{CS}_{2}$ had eluted from the g.c. column (time as determined from previous flame lonization detection measurements) the g.c. column effluent was rerouted to the Beckman IR-102 sample cell and the analog signal from the IR-102 detector amplifier was digltized via program GCIRAD. After sixty full wavelength scans, data acquisition was terminated and the IR data was transformed from contiguous data 
data blocks to random data files, calibrated, converted to absorbance units, and plotted out in the form of a reconstructed gas chromatogram (figure 4 ). We call this a Total Wavelength IR Plot (TWIRP). The $x$-axis is plotted as a function scan number (same as time), i.e. each cycle of the circular variable filter wheel from 2.5 to 14.5 um is ane scan. In this case sixty scans are plotted. The y-axis represents the integrated signal of each single scan, i.e. the summation of each data point over the entire spectral region of one scan; $\left[A_{i} /\right.$ scan. For example, if each scan covered 2.5 to $3.0 \mathrm{um}$ and a data point was taken at every $0.1 \mathrm{um}$, the result would be:

$$
\begin{aligned}
& \operatorname{scan} \# 1=A_{2.5}+A_{2.6}+A_{2.7}+A_{2.8}+A_{2.9}+A_{3.0} \\
& \operatorname{scan} \# 2=A_{2.5}+A_{2.6}+A_{2.7}+A_{2.8}+A_{2.9}+A_{3} .0 \\
& \operatorname{scan} \# 3=A_{2.5}+A_{2.6}+A_{2.7}+A_{2.8}+A_{2.9}+A_{3} .0
\end{aligned}
$$

In this actual case the following would be represented:

$$
\operatorname{scan} \# \mathrm{xxx}=\mathrm{A}_{2.5}+\mathrm{A}_{2.6}+\mathrm{A}_{2.7}+\ldots \ldots \mathrm{A}_{14.5}
$$

or in other words:

$$
14.5
$$

$\operatorname{scan} \# \mathbf{x x x}=\sum \mathrm{A}_{\mathbf{i}}$

$$
i=2.5
$$


The $\sum A_{i}$ 's are then normalized and plotted as a function of increasing scan number and we end up with a reconstructed gas chromatogram or a TWIRP. From this TWIRP, the number of compounds in the injected mixture can be easily seen. Of course the compounds need to have IR active groups to cause a signal on the IR detector. In this initial case, after sixty scans, there is one TWIRP peak starting at scan \#25. Figure 5 shows the IR spectra associated with the scan numbers $22,24,25,26$, and 28 plotted as a function of IR intensity vs wavenumber. Scan \#22 is instrument background and since this is a single beam spectrometer the spectrum is due to ambient $\mathrm{OO}_{2}$ and $\mathrm{H}_{2} \mathrm{O}$. At scan \#24 however a distinctly different spectrum is seen and its intensity continues to increase at scan \#25. At scan \#28 the sample has completely eluted from the g.c. column thru the cell and all that is left is ambient background. These two figures would give two significant pieces of information for identification of an unknown sample. From having previously characterized the SP-2250 column, knowing the g.c. oven temperature is at $150^{\circ} \mathrm{C}$, and seeing the sample elute after 24 scans (144seconds), this would identify it as a low boiling compound. Then by examining the IR spectrum and looking up the wavelengths of the absorbance bands a preliminary identification of the eluting compound would be made. Further chemical analysis would confirm that finding. Similar runs were performed for acetone, methanol, carbon tetrachloride, and benzene.

Having thus demonstrated the GC/IR system on one camponent solutions 


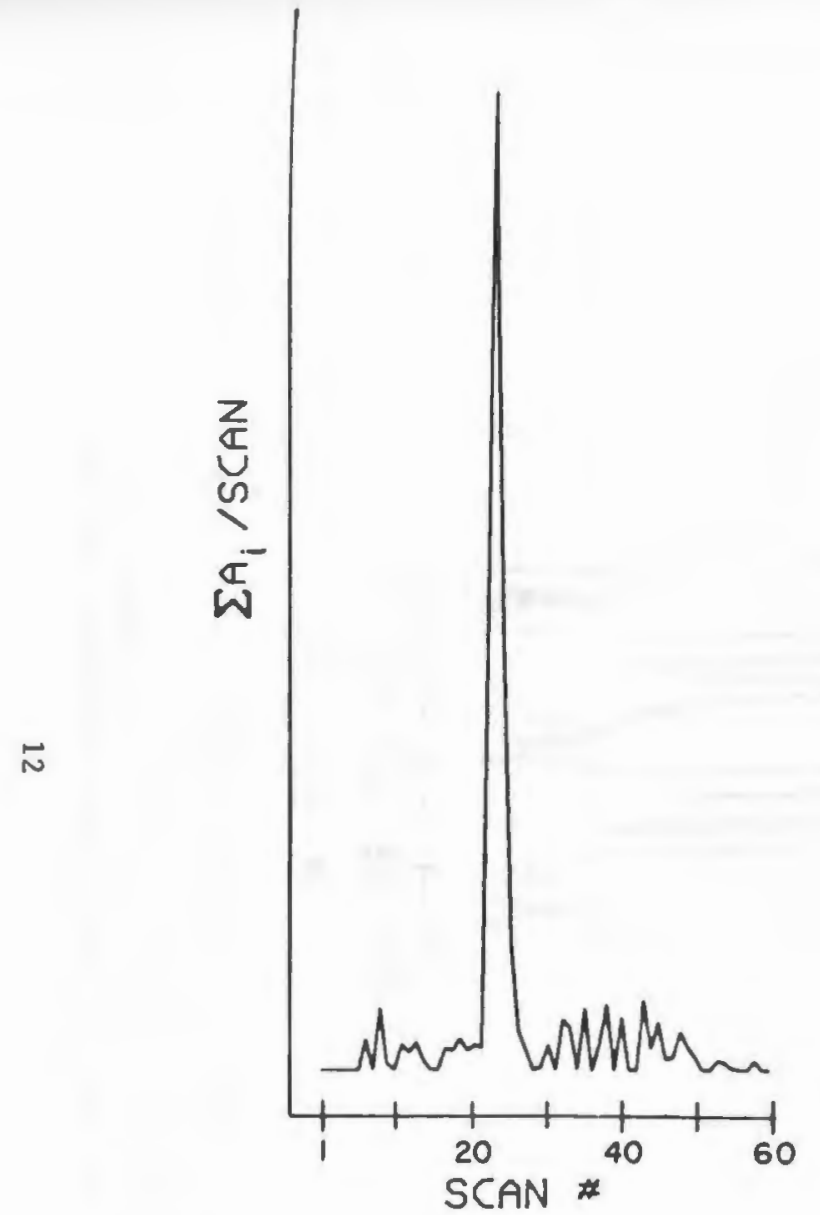

Figure 4. TWIRP (Total Wavelength IR Plot) A reconstructed gas chomatogram
SCAN $=22$<smiles>CCCCCC</smiles><smiles>CCCCCC</smiles><smiles>CCCCCCC</smiles>

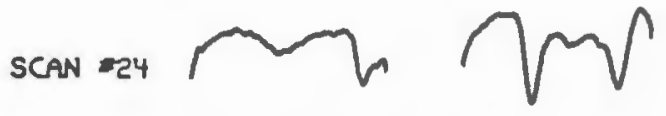

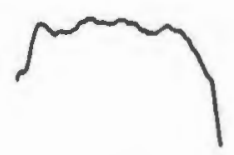
SCAN $=25$<smiles>CCCCCCC</smiles><smiles>CCCCCCCCCC</smiles><smiles>CCCCCCCCC</smiles><smiles>CCCCCCCCCCCCCCCCCCC</smiles><smiles>CCCCCCCC</smiles><smiles>CCCCCCC</smiles>
SCAN $=28$

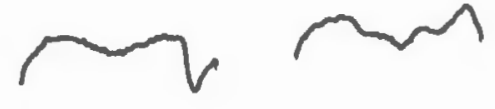

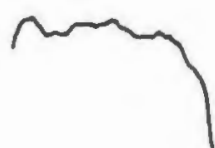

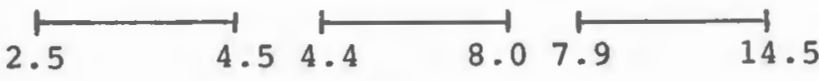

$$
\begin{aligned}
& \text { Wavelength (um) }
\end{aligned}
$$

Figure 5. Spectral plots corresponding to the TWIRP peak In figure 4 


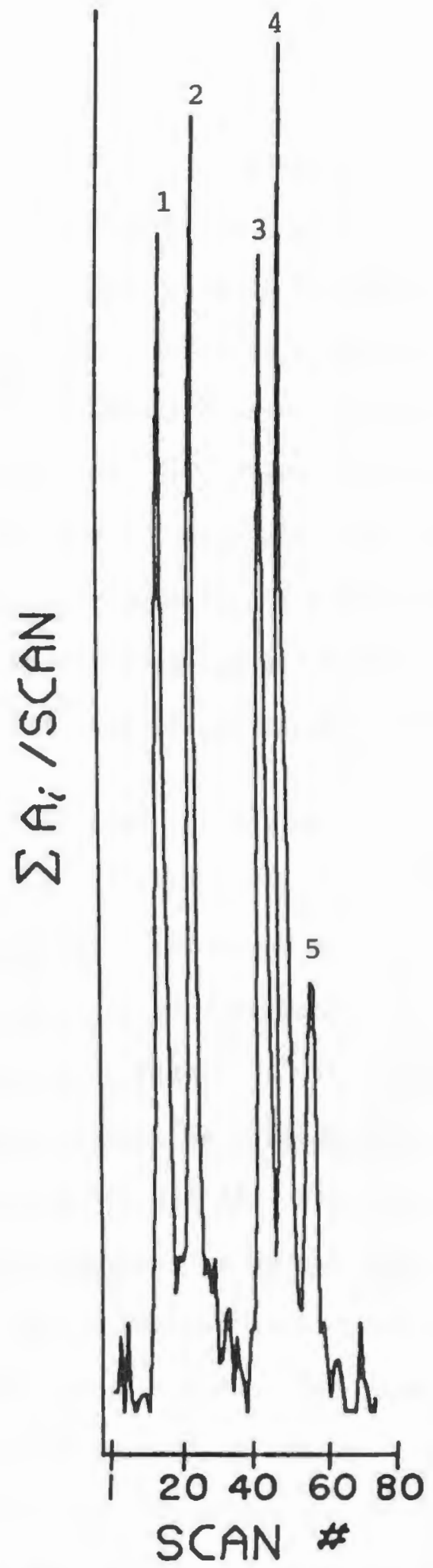

Figure 6. TWIRP for a five component mixture consisting of (1) methanol, (2) acetone, (3) chloroform, (4) carbon tetrachloride, and (5) benzene in a carbon disulfide solution ( $\mathrm{CS}_{2}$ vented to atmosphere). 
the next step was the analysis of a multi-component mixture. Five compounds closely related in bolling points were chosen to provide a test as to whether we could separate and obtain spectra on-the-f1y of rapidly eluting compounds. The five components, acetone b.p. $56^{\circ} \mathrm{C}$, chloroform b.p. $61^{\circ} \mathrm{C}$, methanol b.p. $64^{\circ} \mathrm{C}$, carbon tetrachloride b.p. $76^{\circ} \mathrm{C}$, and benzene b.p. $80^{\circ} \mathrm{C}$ were mixed in equal volumes into a carbon disulfide solution. This solution not only provided a stringent test as far as separation and identification but was also typical of compounds found in hazardous waste sites and which must be analyzed in an actual facility prior to the start of any cleanup operations.

The same procedure used for the one component solution was used for this five component analysis. The $\mathrm{CS}_{2}$ was vented and the scan and acquisition initiated. Spectral scans were recorded, stored on disk, callbrated, converted to absorbance units, and the TWIRP displayed on the plotter as shown in figure 6. It is immediately evident that we have a five component mixture as evidenced by the reconstructed $g \cdot c$. peaks at scan $\# 14,22,41,47$, and 55. Even though we had a known solution of equal amounts of compounds, we do not necessarily end up with equal intensity peaks. This is because each component has different IR active groups and absorbance coefficlents. For example, $\operatorname{cS}_{2}$ has very 11 ttle IR aborbance in the 2.5 to $14.5 \mathrm{um}$ region compared to acetone which has strong IR absorbance. Therefore the IR-102 detector would not "see" very much $\mathrm{CS}_{2}$ relative to acetone and the resultant integrated IR signal would be very small. The same is true for all compounds and since the TWIRP is normalized to the strongest integrated signal, the 
reconstructed g.c. peaks are all relative in intensity.

Agaln as done prevfously the spectra assoclated with each reconstructed g.c. peak are plotted out as a function of \% transmission vs wavelength (f1gure 7). Scan $\|_{1} 1$ is the 1nstrument background and the subsequent scans correspond to the five g.c. peaks. Figures $8,9,10,11,12$, and 13 are the spectra displayed for more detailed analysis.

Scan \#1: Instrument background. Absorptions correspond to atmospheric $\mathrm{H}_{2} \mathrm{O}$ and $\mathrm{CO}_{2}$.

Scan 非14: Represents TWIRP peak 非 wh1ch is due to methanol.

Scan 非2: Represents TWIRP peak 非 wh1ch 1s due to acetone.

Scan \#41: Represents TWIRP peak \#3 wh1ch 1s due to chloroform.

Scan $\# 47$ : Represents TWIRP peak $\# 4$ wh1ch is due to carbon tetrachloride.

Scan 非5: Represents TWIRP peak 非 wh1ch 1s due to benzene.

For a real world application we would not know aprlorl what each IR spectrum is due to, but there is significant information contained in the GC/IR TWIRP and spectra to allow an educated selection of possible candidates. In scan $\equiv_{14}$ there 18 strong absorption at 3.0 um which 1 s very 
$v^{M r m p o n m o n}$

RMM

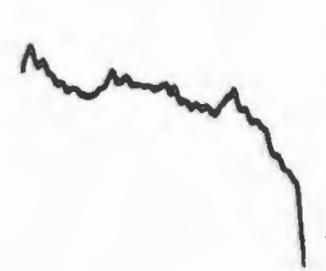

SCAN $=1$

$v^{M}$

Mm

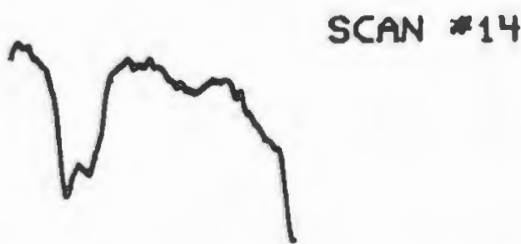

G

$\stackrel{n}{n} N$

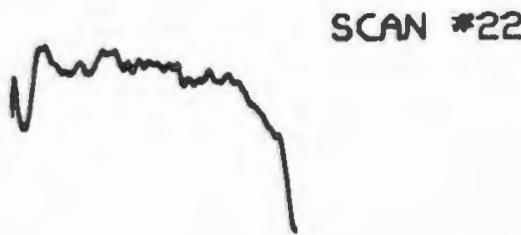

Mrmunary<smiles>CCCCCCCCCCCCCCCCCC</smiles>

SCAN 41

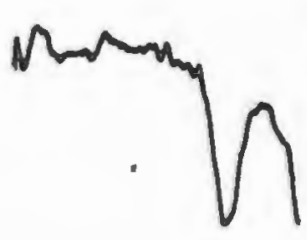

Mrumangry
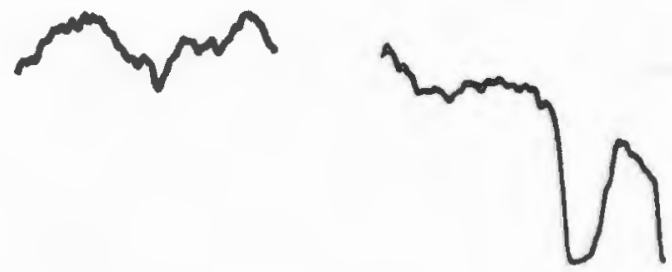

SCAN $: 47$
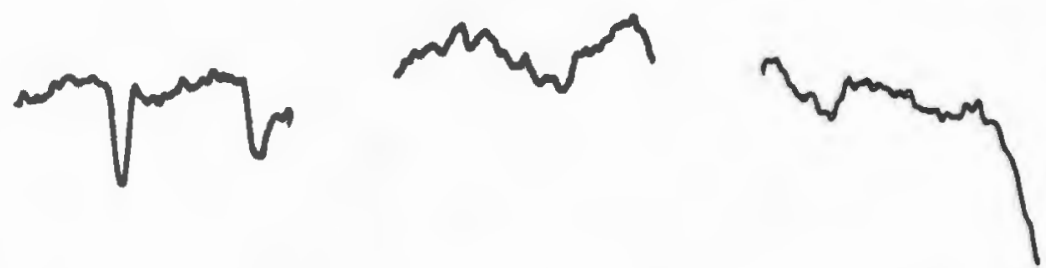

SCAN $=55$
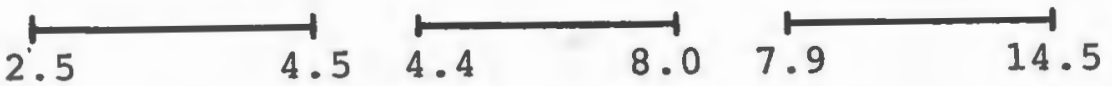

Wavelength (um)

Figure 7. Infrared spectra for the five component mixture corresponding to the TWIRP in figure 6. Scan \#1 is the instrument background while scans $14,22,41,47$, and 55 correspond to the

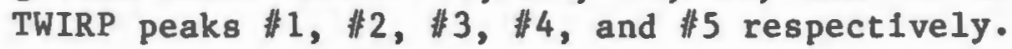




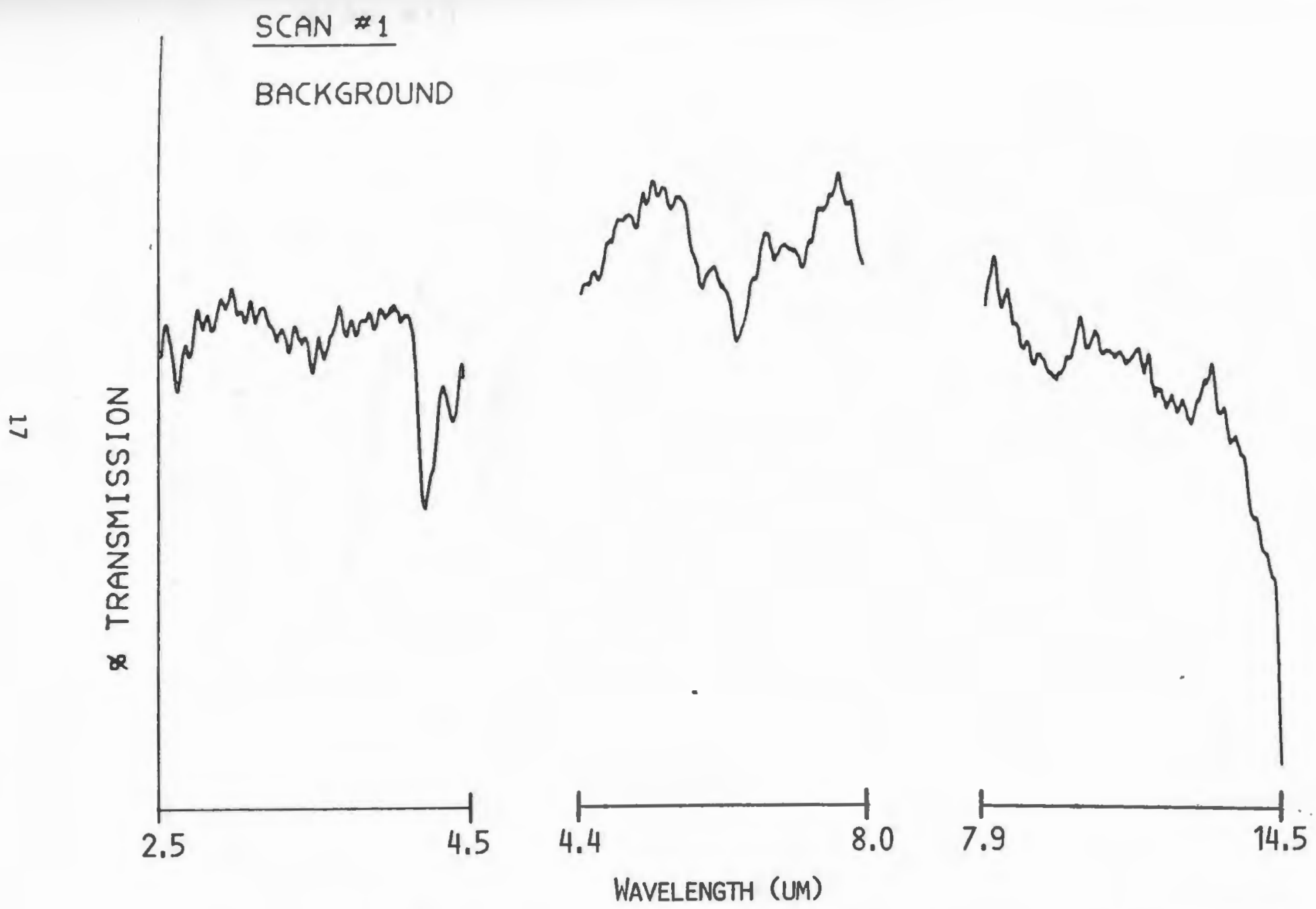

Figure 8. Infrared spectrum for scan 1 showing instrument background. Absorptions are due to ambient $\mathrm{CO}_{2}$ and $\mathrm{H}_{2} \mathrm{O}$. 


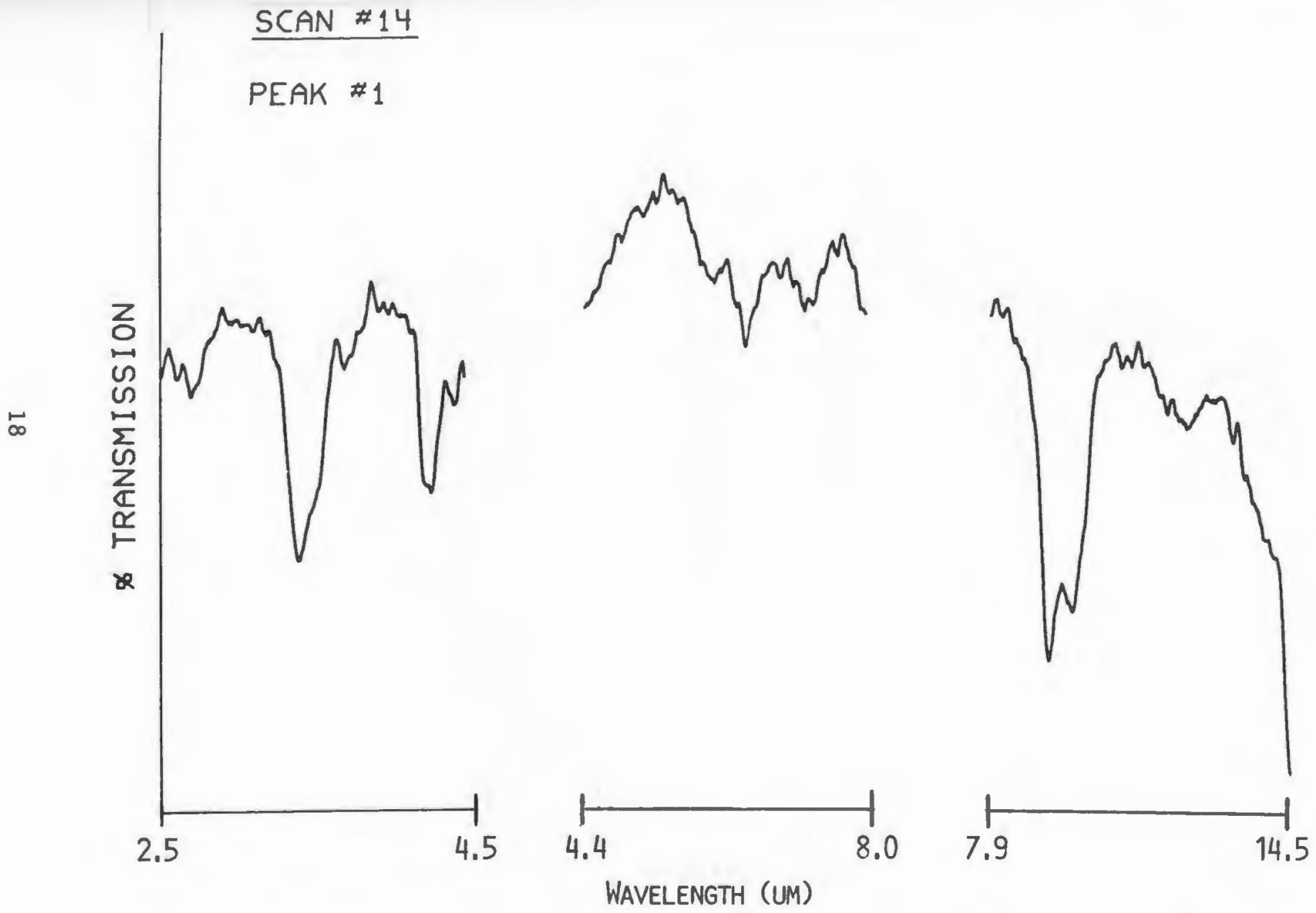

Figure 9. Infrared spectrum for scan \#14 which corresponds to the first TWIRP peak of figure 6 and is due to methanol. 


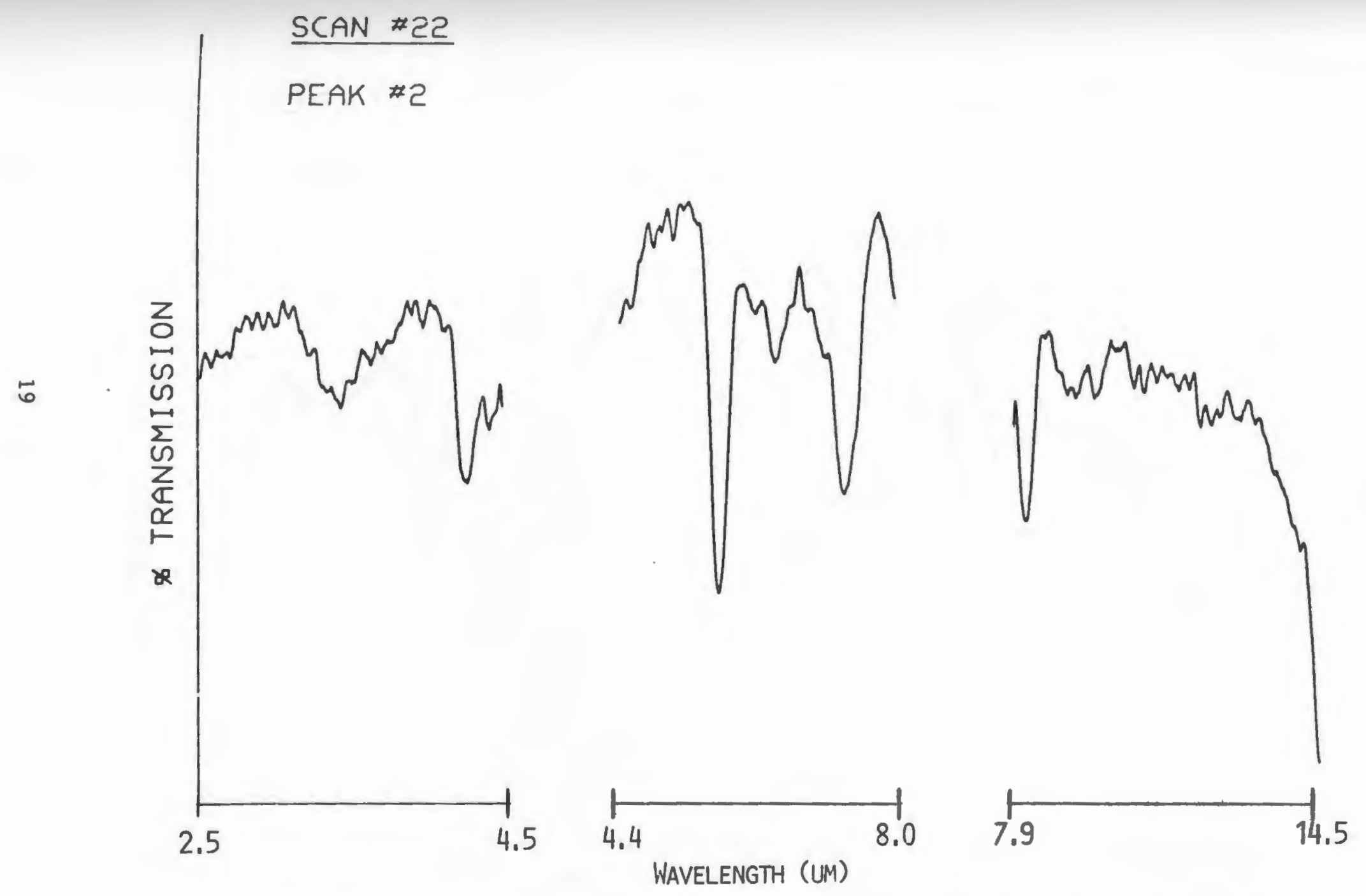

Figure 10. Infrared spectrum for scan \#22 which corresponds to the second TWIRP peak of figure 6 and is due to acetone. 


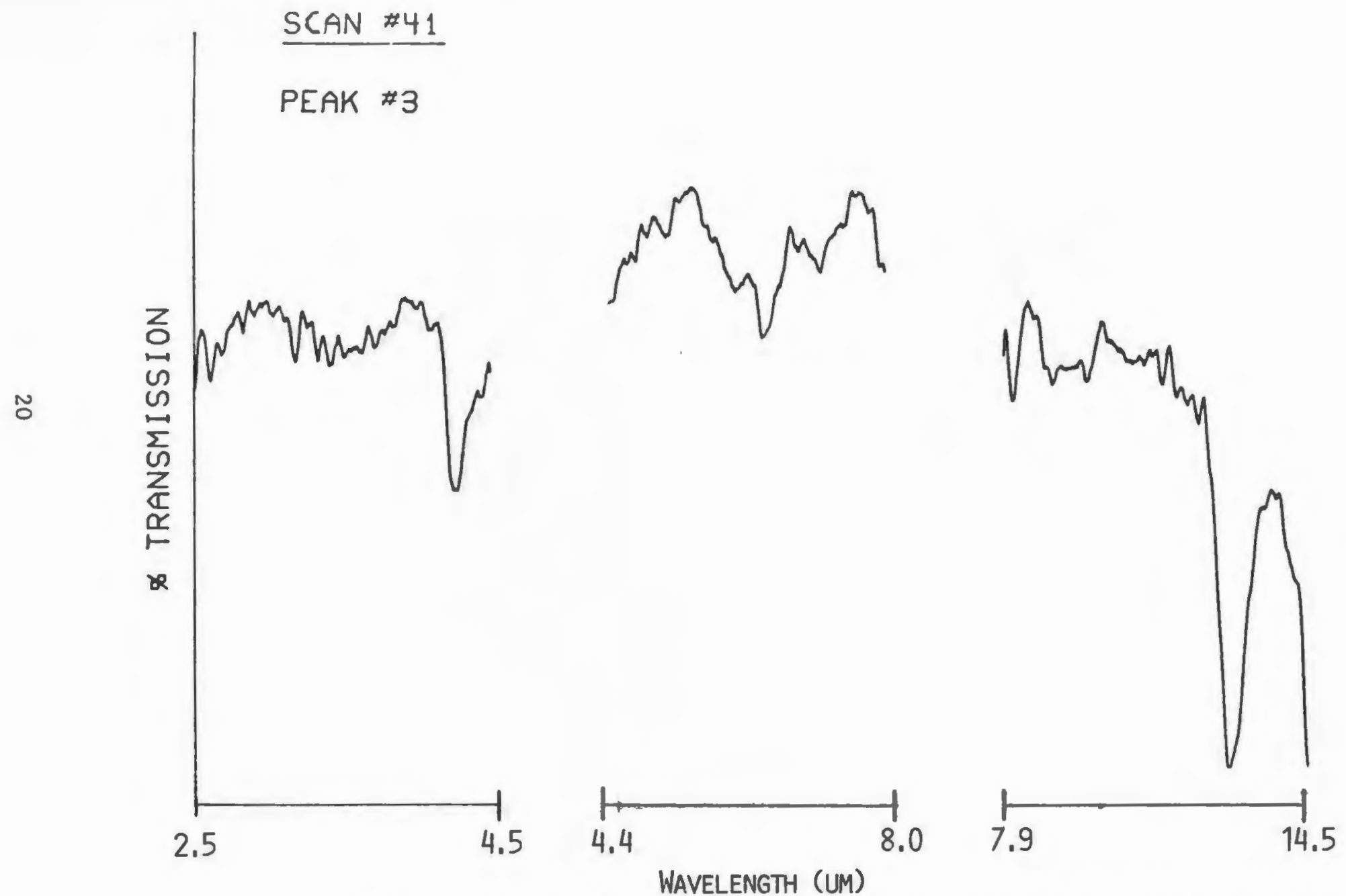

Figure 11. Infrared spectrum for scan $\$ 41$ which corresponds to the third TWIRP peak of figure 6 and is due to chloroform. 


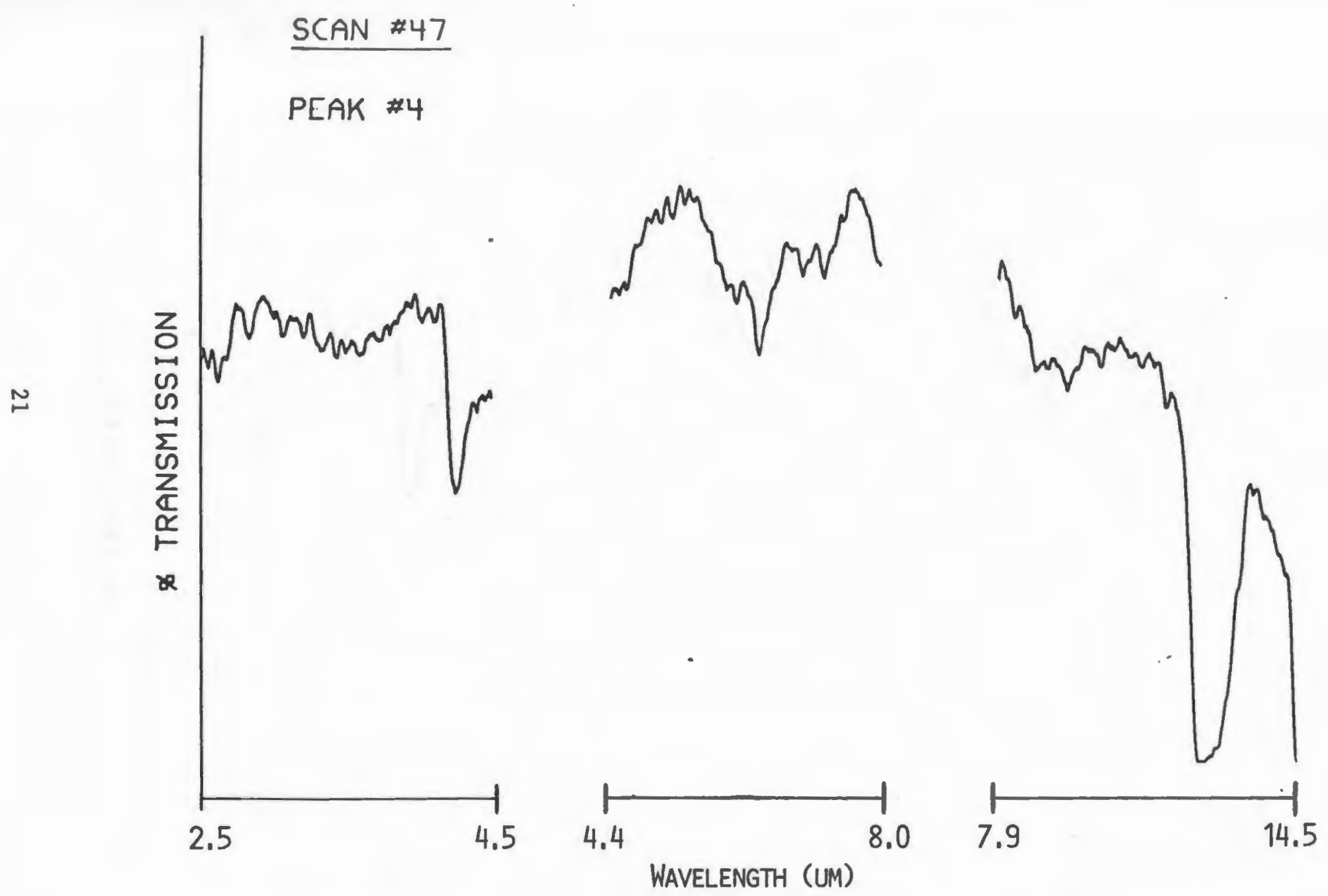

Figure 12. Infrared spectrum for scan $\$ 44$ which corresponds to the fourth TWIRP peak of figure 6 and is due to carbon tetrachloride. 


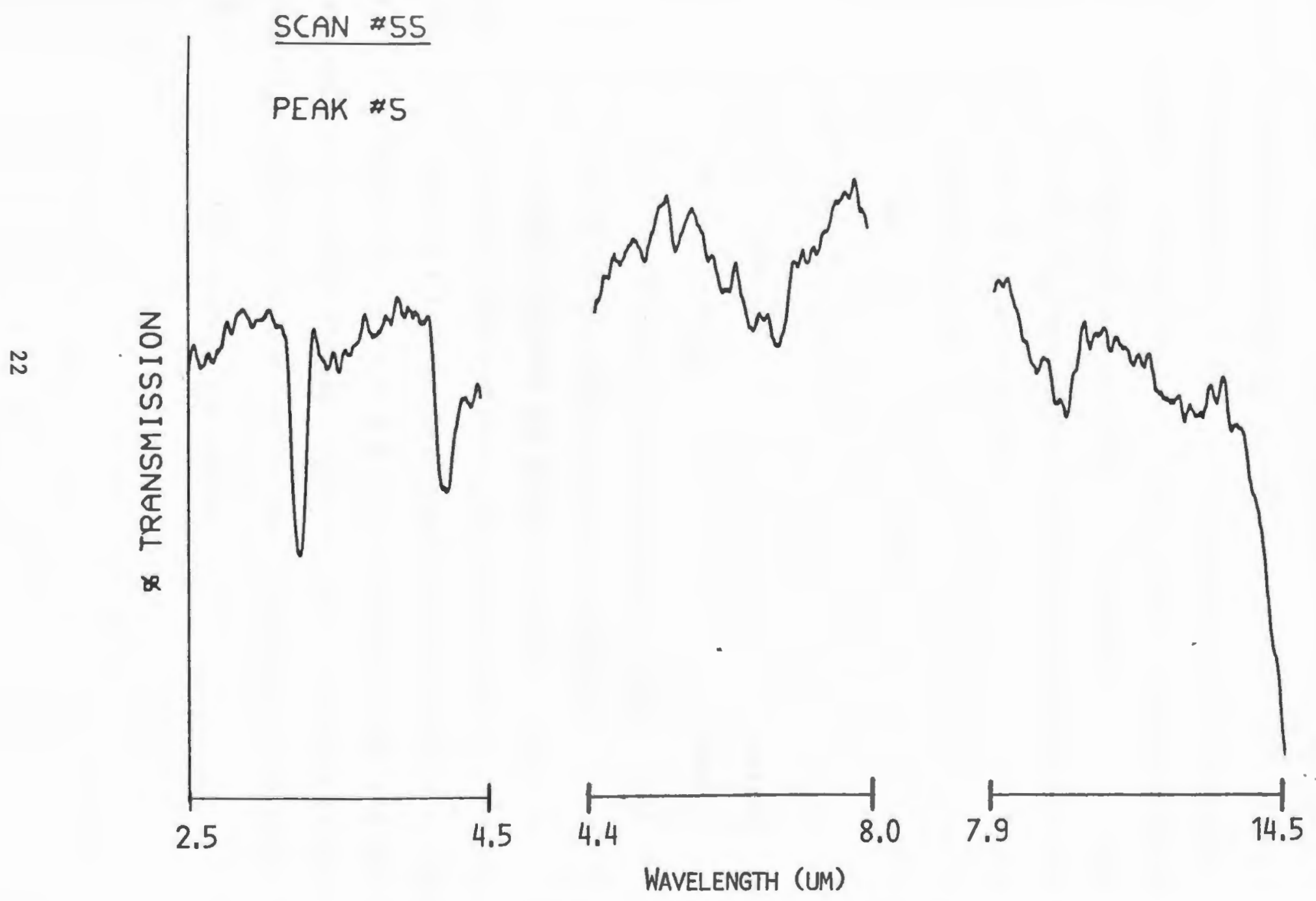

Figure 13. Infrared spectrum for scan \#55 which corresponds to the fifth TWIRP peak of figure 6 and is due to benzene. 
characteristic of an $-\mathrm{OH}$ stretch such as in an alcohol. Th1s coupled with the fact that 1 is a low bolling point compound narrows the search for an unknown compound considerably. For scan \#55 an absorption at 3.2 um signifies an aromatic compound. Thus, based on very little interpretation the analyst would know the unknown mixture contalns flve low boillng compounds and that one is an alcohol and one is an aromatic. If only a gc was avallable, the analyst would know there were five compounds in the mixture and that they were low bolling. The additional IR data provides a great amount of valuable Information and significantly narrows the chloce of possible candidates for positive identification.

During this investigation we also conducted a comparision between the GC/IR TWIRP and a standard gc flame lonization detector (FID). The same five component mixture used previously was analyzed with the gc column reconnected to the FID as in normal gc operation. Figure 14 shows the comparision between the normal gc output and the TWIRP from the GC/IR. Both plots are simllar in that they identify a five component mixture and just as the integrated IR detector signal for each particular compound is different so it is for the FID where the electron rich aromatic ring of benzene gives a much stronger signal than the other compounds. The FID analysis confirms the GC/IR results in regards to the number of components in the mixture. 

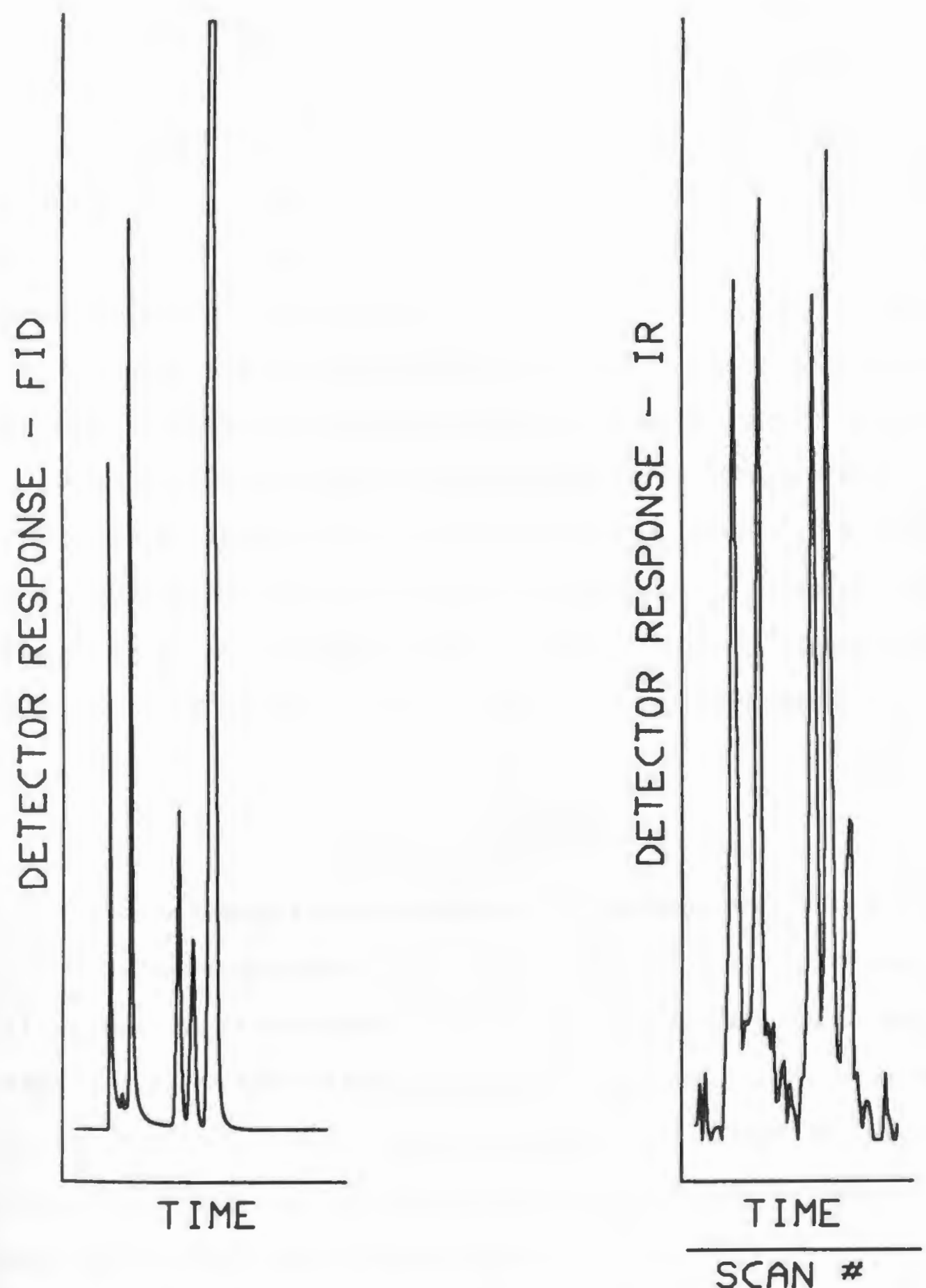

Figure 14. Comparision of a gas chromatogram (flame ionization detector) to the TWIRP reconstructed gas chromatogram of a five component mixture of acetone, chloroform, methanol, carbon tetrachloride, and benzene. 
While checking the reproducibility of the CVF scan and data acquisition we decided to try signal averaging the spectra to decrease the noise in a plotted spectrum. Figure 15 shows the original spectrum and an averaged spectrum where four spectra were added together and then signal averaged. As can be seen there is a noticable reduction in nolse (the original spectra were made nolsy on purpose by running at a higher than normal amplifier gain). Also a three point smooth technique was used and again this resulted in nolse reduction. As in any case when spectra are digitized and stored in memory a wide varlety of signal processing options are possible including expansion, subtraction, and spectral searches to match an unknown to a known. In fact a laboratory which does routine analysis would maintain a spectral library of known compounds as well as a listing of ge elution times for a given gc column at known temperatures and flow rates.

\section{Conclusion}

We have demonstrated a simple GC/IR/Computer system to analyze multi-component mixtures "on-the-fly". The system is demonstrated on a five component mixture with closely related bolling points. The resulting reconstructed gas chromatograms and associated IR spectra provide sufficent information to identify each of the five components. This GC/IR consists of a rugged clrcular varlable filter spectrometer and is 1deally suited for field use. 


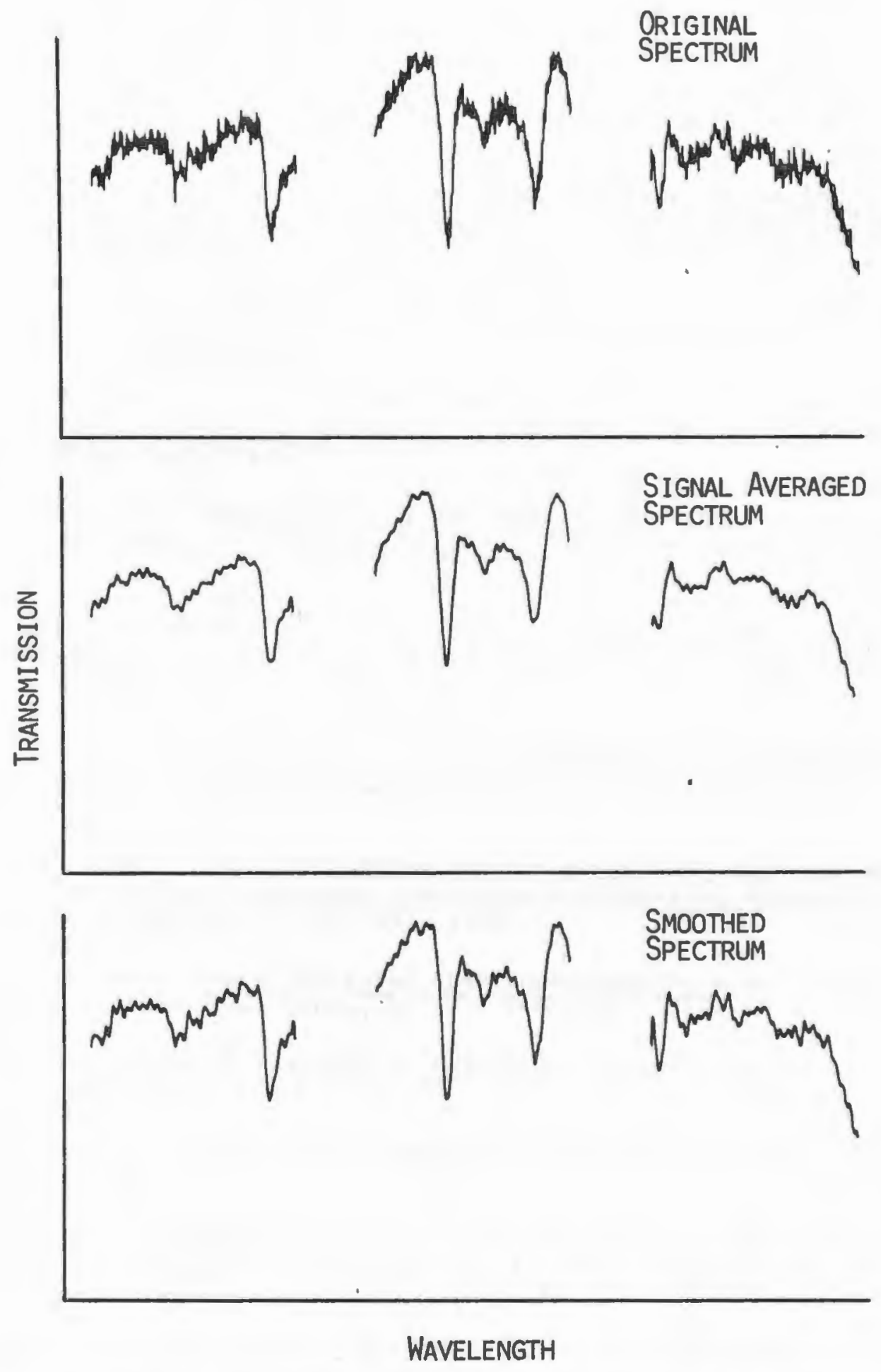

Figure 15. Computer processing of Beckman IR-102 spectra demonstrating signal averaging and smoothing techniques. 


\section{REFERENCES}

1. J.G. Grassel1i and M.K. Snavely, Analysis of Organic Reaction Products by Combined Infrared - Gas Chromatography Techniques, Applied Spectroscopy, (6), $90-4,1952$.

2. H.E. Bellis and E.J. Slowinski, Jr., Application of Vapor Chromatography to Infrared Spectroscopy of Liquids, J. Chem. Phys., (25), 794, 1956.

3. D.M.W. Anderson and J.L. Duncan, Identification and Quantitative Estimation of Gas-Chromatography Fractions by Vapor-Phase Infrared Spectroscopy, Chem. \& Ind., 662, 1958.

4. D.M.W. Anderson, Applications of Infrared Spectroscopy: The Identification and Determination of Gas-Chromatographic Fractions, Analyst, (84), 50-5, 1959.

5. W.L. Senn, Jr. and H.V. Drushe1, Organic Composition Analysis by Combination Gas-Chromatography with Infrared Spectroscopy, Anal. Chem. Acta, (25), 328-33, 1961.

6. P.A. Wilks, Jr. and R.A. Brown, Construction and Performance of an Infrared Chromatographic Fraction Analyzer, Analytical Chemistry, 36(10), 1896-9, 1964.

7. K.H. Kubeczka, Simple Arrangement for the Collection of Very Sma11, Gas Chromatographically Seperated Substances for Infrared Spectroscopy, Naturwissenschaften, 52(14), 492, 1965.

8. G.P. Nicolaisis, Use of Infrared Spectrophotometry in Gas Chromatography: New Designs, Kem. Teollisuns, 23(12), 1095-102, 1966.

9. M.J.D. Low, Rapid IR Analysis of Gas-Chromatography Peaks, Chem. Commun., (12), 371-2, 1966 .

10. N.W.R. Daniels, GC-IR (Gas-Chromatography-Infrared) Microanalysis, Column, $2(1), 2-5,1967$.

11. H. Bober and K. Buerner, Optimum Operation Conditions for the Combination of a Gas Chromatograph with the Fast Scanning Spectrophotometer IR-102,

Fresenius Z. Ana1. Chem, 238(1), 1-19, 1968.

12. R.J. Bell, Introductory Fourier Transform Spectroscopy, Academic Press, 1972. 


\section{BIBLIOGRAPHY}

1. Ahmadjian, M. and Brown, C.W., IR/GC with an Inexpensive Non-Dispersive Spectrometer, The Pittsburgh Conference on Analytical Chemistry and Applied Spectroscopy, 1980.

2. Anderson, D.M.W., Applications of Infrared Spectroscopy: The Identification and Determination of Gas-Chromatographic Fractions, Analyst, (84), $\overline{50-5,1959 .}$

3. Anderson, D.M.W. and Duncan, J.L., Identification and Quantitative Estimation of Gas-Chromatography Fractions by Vapor-Phase Infrared Spectroscopy, Chem. \& Ind., 662, 1958.

4. Azarraga, L.V., Gold Coating of Glass Tubes for Gas Chromatography Fourier Transform Infrared Spectroscopy "Light P1pe" Gas Cells, App1. Spectry., 34(2), 224-5, 1980.

5. Azarraga, L.V. and McCal1, Infrared Fourler Transform Spectrometry of Gas Chromatography Effluent8, EPA-660/2-73-034, 1974.

6. Bell1s, H.E., and Slowinski, E.J. Jr., Application of Vapor Chromatography to Infrared Spectroscopy of Liquids, J. Chem. Phys., (25), 794, 1956.

7. Bober, H. and Buerner, K., Optimum Operation Conditions for the Combination of a Gas Chromatograph with the Fast Scanning Spectrophotometer IR-102, Fresenlus Z. Anal. Chem, 238(1), 1-19, 1968.

8. Brown, R.A., Kelliher, J.M., James, M., Helg1, J.J., Warren, C.W., and Charles, W., Rapid Scan Infrared Spectrometer for Operation with Support Coated Open Tubular or Packed Column Gas Chromatographs, Ana1. Chem., 43(3), 353-8, 1971.

9. Daniels, N.W.R., GC-IR (Gas-Chromatography-Infrared) Microanalysis, Column, 2(1), 2-5, 1967. Fresenius Z. Anal. Chem, 238(1), 1-19, 1968.

10. Difkstra, G., Coupling of a Gas Chromatograph with an IR Spectrometer, Lab. Instum., 10(1), 19-20,23, 1974 .

11. Grassel11, J.G. and Snavely, M.K., Analysis of Organic Reaction Products by Combined Infrared - Gas Chromatography Techniques, Applied Spectroscopy, (6), 90-4, 1952 .

12. Kizer, K.L., GC/IR Analys is, Amer. Lab., 5(6), 40-2, 44-5, 1973. 
13. Krakow, B., Continual Analysis of Gas Chromatographic Effluents by Repetitive Infrared Scanning, Anal- Chem., 41(6) • 815-19, 1969 .

14. Kubeczka, K.H., Simple Arrangement for the Collection of Very Sma11, Gas Chromatographically Seperated Substances for Infrared Spectroscopy, Naturwissenschaften, 52(14), 492, 1965.

15. Low, M.J.D., Rapid IR Analysis of Gas-Chromatography Peaks, Chem. Commun., (12), 371-2, 1966 .

16. Nicola1sis,G.P., Use of Infrared Spectrophotometry in Gas Chromatography: New Designs, Kem. Teol11suns, 23(12), 1095-102, 1966.

17. Pendry, A., Automated GLC/IR Analysis, Spectrovision, 19, 5-8, 1968.

18. Penzlas, G.J., and Boyle, M.J., Comb1ning Infrared and Gas Chromatography for On-L1ne Analysis, Amer. Lab., (Oct), 53-9, 1973.

19. Senn, W.L. Jr. and Drushe1, H.V., Organic Composition Analysis by Combination Gas-Chromatography with Infrared Spectroscopy, Anal. Chem. Acta, (25), 328-33, 1961.

20. Shaps, R. and 0. Dannhauser, GC-IR Coupling System, Chem-Anlagen Verfahren, (9), 94, 101,103, 1976.

21. Skoog, D.A. and West, D.M., Princlples of Instrumental Analys1s, 1980.

22. Wall, D.L. and Mantz, A.W., HIgh Sens1t1vity Infrared Spectroscopy of Gas Chromatographic Peaks, App1. Spectry, 31(6), 552-60, 1977.

23. W11k1ns, C.L., G1ss, G.N., Brissey, G.M., and Stelner, S., Direct Linked Gas Chromatography-Fourler Transform Infrared-Mass spectrometer System, Ana1. Chem., 53, 113-17, 1981.

24. W11ks, P.A. Jr., Gas Chromatography and Infrared Spectroscopy: A Potent Analyt1cal Team, Amer. Lab., (March), 14-20, 1969.

25. W11ks, P.A. Jr. and Brown, R.A., Construction and Performance of an Infrared Chromatographlc Fraction Analyzer, Analytical Chemistry, 36(10), 1896-9, 1964 . 


\section{APPENDIX}

\section{Program Listings and Descripti ns}

These computer programs were written for use on a Data General Corporation (IGC) NOVA $3 / 12$ mini-comuter system with an analog digital converter. The programs were written in Fortran and DGC assembly language. 
Program: GCIR.FR

Purpose: This is the main controller program, 1.e. executor, for the GC/IR/Computer System.

Method: GCIR.FR allows speclfic run time programs to be executed via swap commands.

Input: The user needs to specify at the prompt which real time programs are to be run. They are:

1. Data acquisition of the Infrared data from the IR-102 signal conditioning electronics.

2. Wavelength callbration of the spectral data.

3. Signal averaging.

4. Plotting of the reconstructed gas chromatograms, TWIRPs, and spectra.

Output: User prompts for the above functions. 
THLS IS THE MAIN COMTFOLLEF PFOGFAM FOF THE GOTF CONFUTE:

SYSTEM THE FUN TIME FFOGRAMS AFE DROUGHT INTO EXEOUTTON UTA SWAF COMMANIS. THE FOLLOWTNG FFOBVAMS ALOMO WTTH THE TR

SUBROUTINES ANI LIBFARIES AFE USED:

GCTFAOI + FFi

GCIFIAUG, FFi

GCIFELOT + FF

\section{GCIFCALTH+FF}

: TO ACRUTRE DATA ANL STORE THTS MARA lN

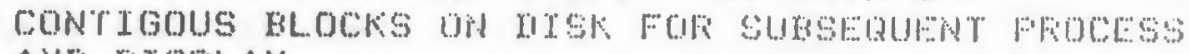
ANII TISFLAY. GCIFSUA. FF ADGCIFi. SF FOFIT + L. E
: TO SICNAL AVEFAGE SFECITRA FOFT • L. B

\section{SCALE}

THE CAALIEFATION IIATA IS THE STOFEL

FOR SUBSEQUENT USE BY THE FLOTTEF FROBKAM. NFLLT . SF

FORT + LE

\author{
FORT LA
}

: TO FLOT OUT SFECTFA

FHLOTTERANS . L.. B

FOFET - L. F

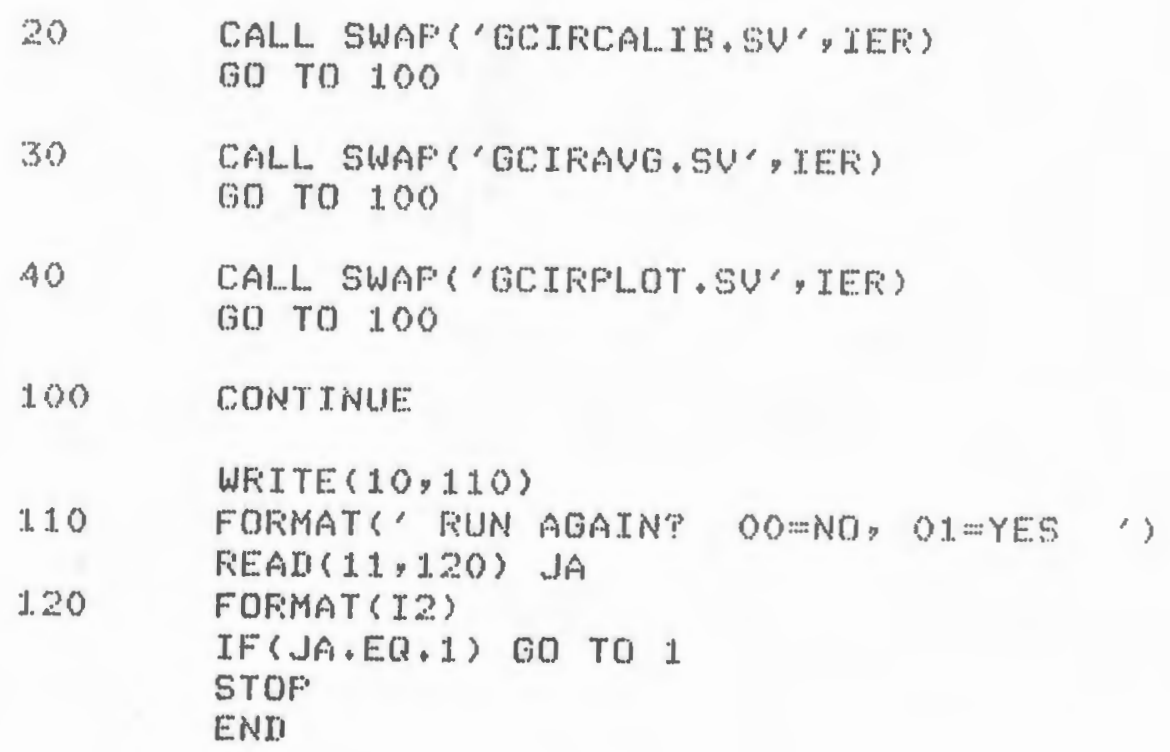




$\begin{array}{ll}\text { TYFE' MATA ACQUISITION } & =01, \\ \text { TYFE'CALIEFATIDN } & =02, \\ \text { TYFE'SIGNAL AUEFAGTNG } & =03, \\ \text { TYFE'FLOTTING } & =04 ;\end{array}$

ACCEFT'? , J

$G 0 \operatorname{TO}(10,20,30,40), \mathrm{J}$

10

CALL SWAF' ('GCIFAI, GU', IER)

CO TO 100 
Program: GCIRAD.FR

Purpose: This program and its subroutines acquire data from the Beckman IR-102 spectrometer.

Method: GCIRAD.FR and 1ts subroutines samples the analog signal from the IR-102 signal conditioning electronics, converts the analog data to digital via the DGC $A D C$, and stores the digitized data on disk for subsequent processing and display.

Input: The user needs to specify a file name into which to sore the data and an ADC sampling rate.

Output: Output are contlguous disk file containing the digitized spectral data from the GC/IR. 
THIS FRO ANI ITS SUBROUTINES ACQUIFE IATA FROM THE GCTFE AT EUEFYY CLOCK TICKCIF TIME DELAY: 1.) A IUATA FOINT IS TAKEN THE IF DETECTOR ELECTFONICS ANII THIS IIATA TS STOFED IN BLOCKS.

SURFOUTINES: GCIFSUE,FR ALGCIR, SR

IIMENSION JSFEC $(10)$, JWAT $(8192)$

WFITE $(10,2)$

$\because$

FOFIMATS' SFECIFUM III? ')

3

FEAI $(11,3)$ JSFEC(1)

FOFMAT (S14)

ACCEPT'A: OF IISK TRANSFEFS TO BE EFFECTEII? "N

ACCEF'T' OF IIATA FTS FEF IISK TFANSFER? ' II ACCEFT' OF CLOCK FULSES BETWEEI IMATA POINTS?', 'T,

IF (I3.ET.256) G0 TO 5

c

I $S=$ \#F IIATA BLOCKS/SCAN

$16=1$

GD TO 30

$5 \quad[13= \pm 3 / 256$

$\mathrm{J} 3=[\mathrm{13}$

R3 $=[13-13$

IF (Fi3) $20,10,20$

1.0 I $6=\sqrt{ } 3$

GD TO 30

$20 \quad 16=53+1$.

30 CONTINUE:

C. IFILE:H OF MATA BLOCKS FEN ENTIEE RUN IF ILE $=I S *(N+3)$

C IT=SIZE OF IIMENSTON IIATA AFFAY $I 7=256 * I 6$

C. SET UF IIATA FILE ON IIISK

CALL. IIF TLW USFEC, IEF)

TYFE' IIFILW IEEF $=$ " IER 


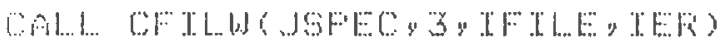

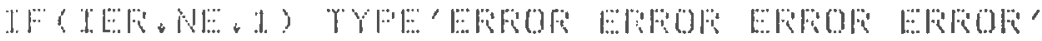

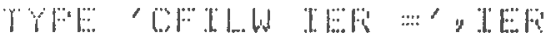

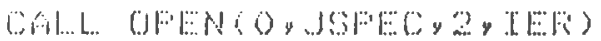

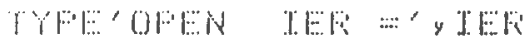

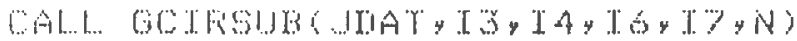

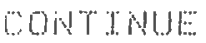

orom

ENy 
Program: GCIRSUB.FR

Purpose: Th1s is a fortran subroutine used by GCIRAD.FR to inftiate data acquisition and write the data onto disk.

Method: Based on the inputs from GCIRAD.FR specifying the file name and the length of time for data acquisition this program will run an assembly language subroutine, ADGCIR.SR, to sample the ADC and write the data out to a disk.

Output: Contiguous data blocks on disk. 
SUBROUTINE FOR GCIRAD.FR (ACQUIRING DATA FROM THE GCIR AND STORING THIS DATA IN CONTIGUOUS DATA BLOCKS ON DISK).

SUBROUTINE GCIRSUB (JDAT, I $3, \mathrm{I} 4, \mathrm{I} 6, \mathrm{I} 7, \mathrm{~N}$ )

DIMENSION JDAT(I7), INFO(256)

COMMON IDAT(8192)

EQUIVALENCE (IDAT ( 1 ), IARRAY)

DO $90 I=1, I 7$

$\operatorname{JDAT}(\mathrm{I})=0$

$\operatorname{INFO}(1)=I 3$

$\operatorname{INFO}(6)=I 4$

$\operatorname{INFO}(11)=I 6$

$\operatorname{INFO}(16)=I 7$

$\operatorname{INFO}(21)=\mathrm{N}$

WRITE $(10,100)$

100 FORMAT(' HIT RETURN TO START DATA ACQUISITION ') $\operatorname{READ}(11,110) \mathrm{KR}$

110 FORMAT(I2)

$\mathrm{J}=2$

$\mathrm{LR}=0$

115

DO 140 IL $=1, N$

CONTINUE

CALL ADGCIR(IARRAY, I4, I3)

130

DO $130 I=1, I 3$

$\operatorname{JDAT}(I)=\operatorname{IDAT}(I)$

CALL WRBLK(0, J, JDAT, I6, IER)

IF (IER.NE.1) TYPE'ERROR ERROR ERROR ERROR'

$J=J+I 6$

$\operatorname{INFO}(21)=I L$

140

CALI WRBLK(0,1, INFO, 1, IER)

$L R=L R+1$

$\operatorname{CALL} \operatorname{WRBLK}(0,1, \operatorname{INFO}, 1$, IER)

TYPE IER

TYPE 'SET UP FOR CALIBRATION RUN? O0-NO, 01-YES'

$\operatorname{READ}(11,110) \mathrm{JCL}$

IF (JCL.EQ.0) GO TO 150

PAUSE HIT RETURN TO START CALIBRATION RUN

GO TO 115

150 CONTINUE

RETURN

STOP

END 
Program: ADGCIR.SR

Purpose: This assembly language subroutine runs the ADC and stores the digitized data into RAM.

Method: ADGCIR.SR samples the ADC channel 非 (multiplexed), stores the data into an accumulator, and then loads the accumulator into a RAM array for subsequent reading and writing by GCIRSUB.FR

Inputs: No user inputs are required.

Output: Digitized infrared spectral data in RAM storage. 
+ TITL. AISCTL

- NREI...

- TXTin 1

- FNT AOHCTE

- ExTu

- ExTin : T

TYY: I 10

C.L.K.:. I. 4

म1901)! 21

FS.:.:

$T . \cdots \cdots 16: \%$

F.

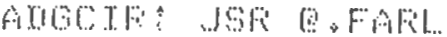

TA 0 , ACO

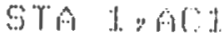

STि 2 \%

L. Iि $0, T+10,3$

STA OMAKEAY

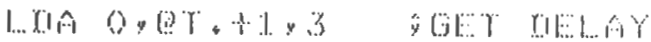

STA 0 . STTME

I...MA 0 ,

STA OYCOUNT

BO: LIA OYCNTF

STA O OUTHER

HEF

- SYSTH

- IIE:LAY

JSF EFE

L.IMA $O$ y C...

IOA 0 , AnCOMU

livio

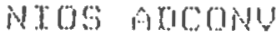

skrrom arrow

JPY,$\cdots$.

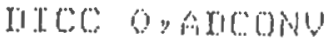

INTEN

LIM 2, AFFAY

GA 0 \% Y

INC ? Y

STA Q AREAY

SUrizl.. 0 \%

[ISZ COLNT

JMF 00

EET: LMA $O$ HACO

LIIA I. $\Rightarrow \mathrm{ACL}$

I...IA ? a

JSF 
Program: GCIRCAL.FR

Purpose: This program transforms the digitized infrared data into spectra.

Method: GCIRCAL.FR calibrates the infrared spectra on a wavelength scale using the O VDC signal between the circular variable filter elements one and three.

Inputs: The user needs to specify the file name the digitized data is stored in and a new file name to write the calibrated data out to.

Output: Output is a random data file containing calibrated spectra. 
THS PRG IS TO DETERMINE THE ARFAY BOUNDAFIES OF TNDIUIDUAL SFECTEA ACQUIFED FROM THE GCIF SYSTE YY UAA PRO BCTR...

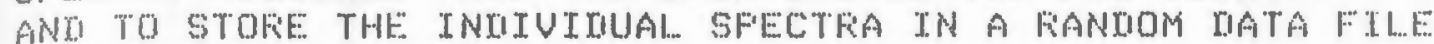

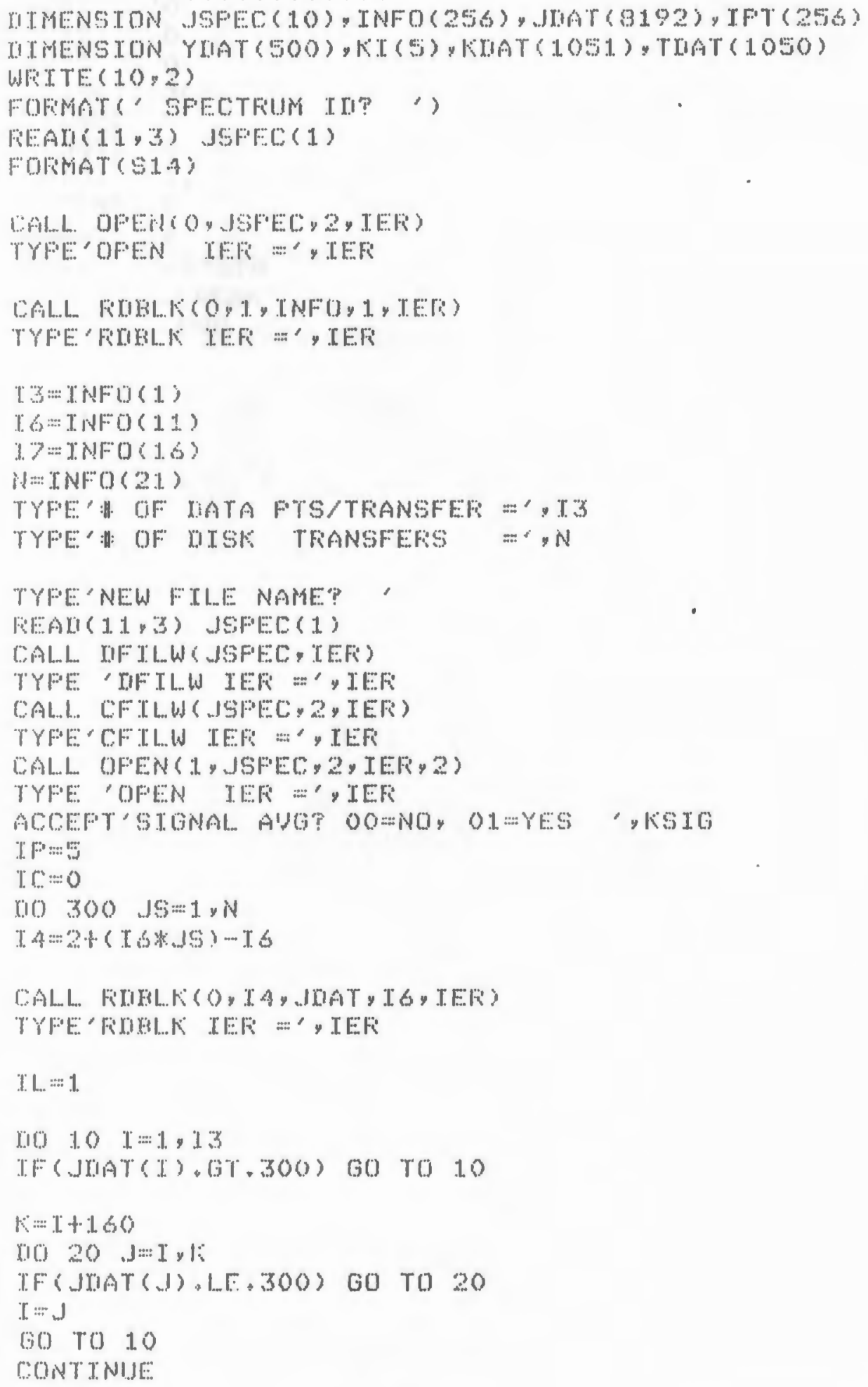


6.:

CiL: : 2

C.H: $\mathrm{B}$

FCO :

il: : 0

AC: : 0

litrive: 300 .

GTME:

Coldot: 0

CNTF 1.

CATEFE: 0

Alvar: 0

EFl: . SYST

- DFEA

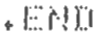


Program: TWIRP.FR

Purpose: This program will plot the reconstucted gas chromatograms.

Method: TWIRP.FR inputs the infrared spectral data from the random files, sums the intensities/spectrum, and plots the sums as a function of scan number.

Inputs: The user needs to specify the file name, noise filtering if desired, and expansion factors for the plotter.

Output: Output is a Total Wavelength IR Plot, TWIRP, i.e. a gas chromatogram. 


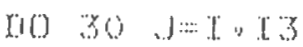

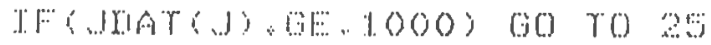

.30

Contrime:

(i) 90 \%

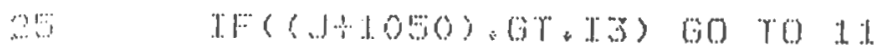

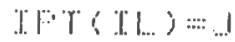

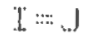

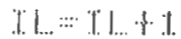

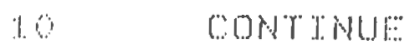

1. 1 ConTtion:

T. I...: TI......

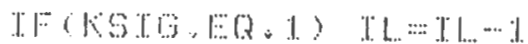

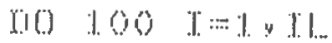

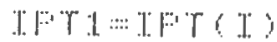

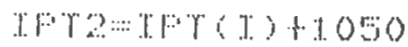

$1 . .:=1$

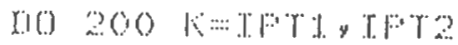

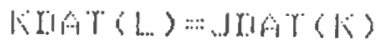

$200 \quad 1 . . \cdots+\ldots+1 . .1$.

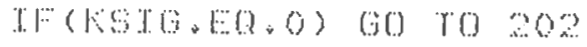

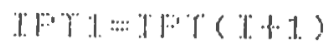

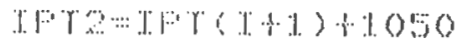

L...:: 1.

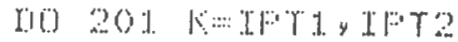

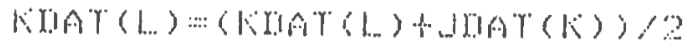

$\therefore 0 \%$

1...:-....+1

GoNTMUE

$T C=\pi+1$

Y stimion:o

MO 210 KN1, 1000

THAT (K) : KrAAT(K)

TrAT (K)

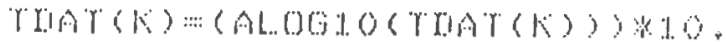

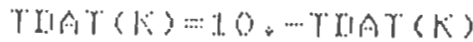

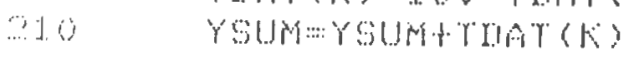

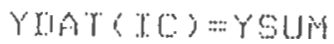

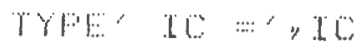

100 Contrente:

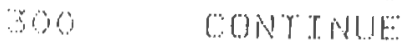




\begin{tabular}{|c|c|}
\hline & $\sqrt{1} \cup:=1$ \\
\hline & 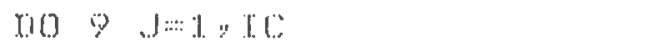 \\
\hline & 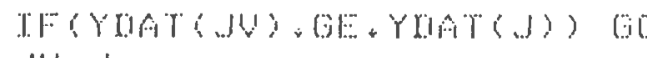 \\
\hline & $.11=: . J$ \\
\hline$?$ & COHTINUE: \\
\hline & $X F=4096 / \operatorname{YHA}(.10)$ \\
\hline & {$[108, \mathrm{~J}=\mathrm{I}, \mathrm{TC}$} \\
\hline 8 & 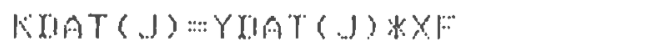 \\
\hline & KNT $(1)=[\ldots$ \\
\hline & 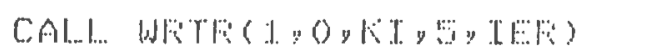 \\
\hline & TYFE 'TEE; $=$, , TEE \\
\hline & CALL. WETR \\
\hline & TYFE , TER :-: IF' IF \\
\hline & TYFE: WXIAT \\
\hline & CALLL. HESEY \\
\hline & STOF \\
\hline & ENI \\
\hline
\end{tabular}

ris 
Program: GCIRSPEC.FR

Purpose: This program plots out individual spectra corresponding from the TWIRP.

Method: GCIRSPEC.FR obtains the calibrated spectral data from the data file and plots it as a function of wavelength.

Inputs: The user needs to specify the file name, the spectrum number, plotter expansion factors.

Output: Infrared spectra 


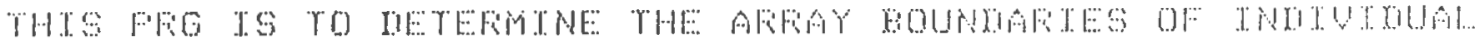

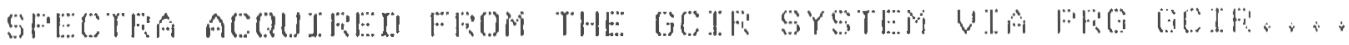

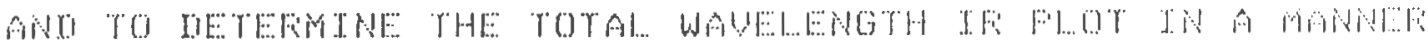

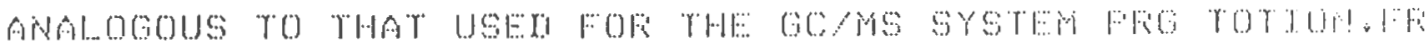

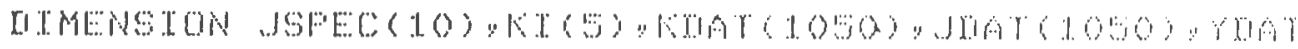

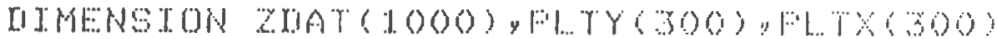

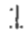

CALI. TNTTTAL $69000.10,3 \% 30.0)$

CoNT TNUE:

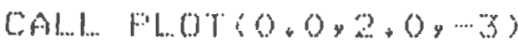

T T $=8.0 / 409,4$

WFT TRE $(10,2)$

2

FOFMAT', SFEETRUM TIT? ,

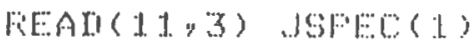

$\because$

FOFIMAT $(S 1,4)$

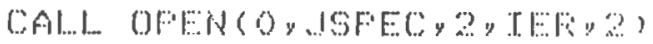

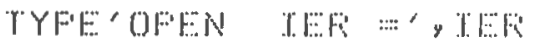

C.ALL... VIIIUW(

TYFE'PREW TEF:

T. $C: \cdots(1, \mathrm{~L}(1)$

TYPE: TC:

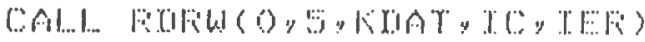

TYFE: 'WFT'F TEE :-: , TEK

(30) TO 401

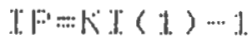

L... $=0$

$I F \gamma=: 5$

TYFE: ON OF SWECTFA $={ }^{\prime}$, IF

ACCEF' STCWAL AVG? OOW

तio 300 T. T. T. T\%

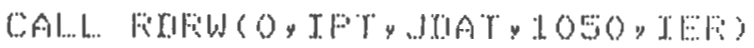

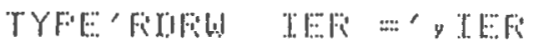

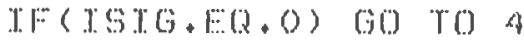

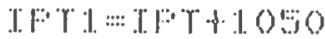

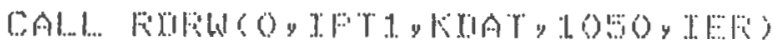

TYFE 'RIFW TER

4

Ysumi: 0.0

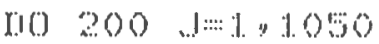

JMAT (.J) :

TF (TSTOEO.O) OO TO 200

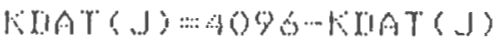

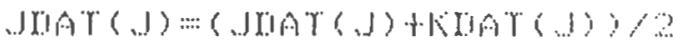

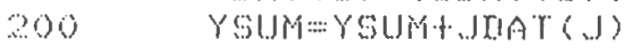


$1, \ldots 1+1$

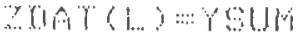

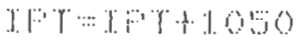

300 contrmente

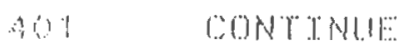

1.... I :

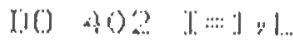

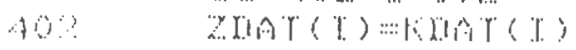

JM $M=1$.

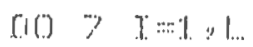

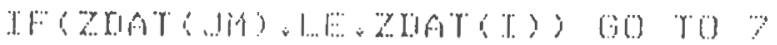

$. J M \cdots:=1$

CONT TNLF:

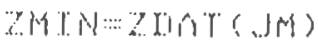

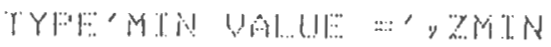

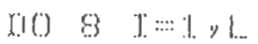

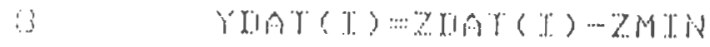

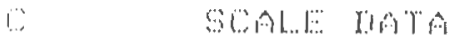

J) 1.

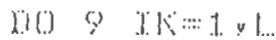

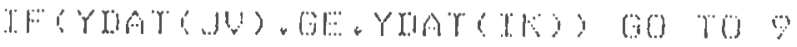

.JU

(O) TWTHE:

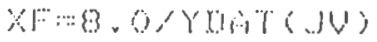

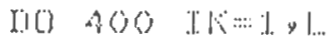

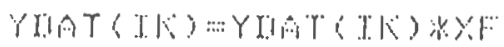

IOO OONTINIE:

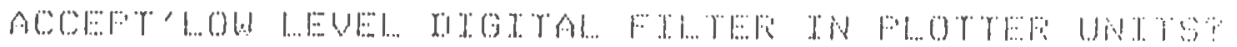
IIO $\quad$ :

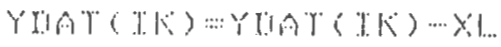

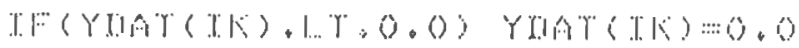

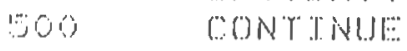

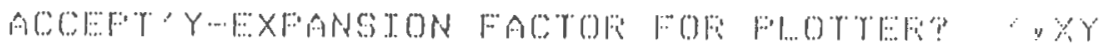

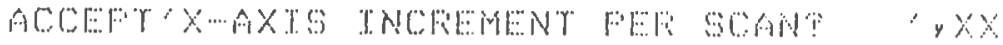

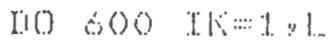

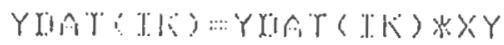

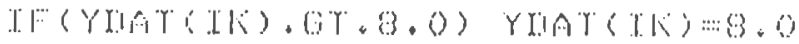

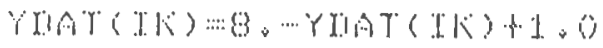

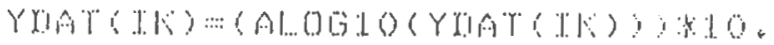

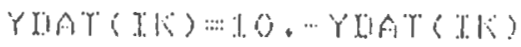

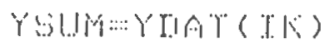

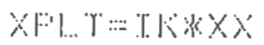

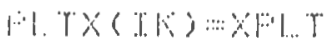

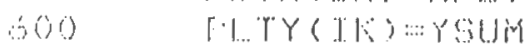

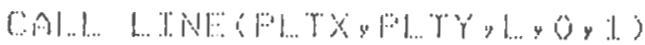




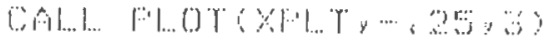

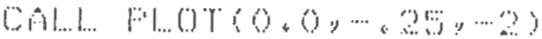

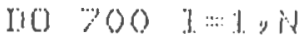

$x \cdots: x \times$

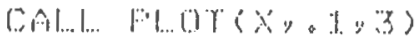

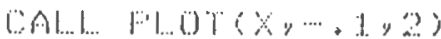

CONTTNLE:

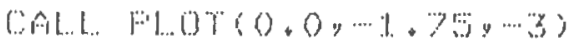

(i) 10 401.

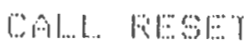

(i) To i.

STOF

EN: 
I.".

t.

THIS FFE IS TO FLOT INIIUI RUAL SFECTKA

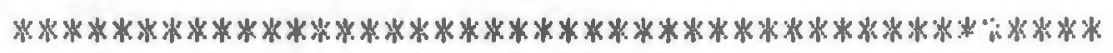

IIMENSION JSFEC(10), INFO(256) y JIAT(1280)

MIMENSION XAXIS(4096), YIAT $(40 \% 6)$, KKI(:)

C.ALL INITIAL $(6,200,10,0,15,0)$

WRTTE $(10,2)$

FOFMAT(' SFECTFUM III? ')

FEAII $(1,3)$ JSFEC: (1)

FOFMAT (S.1.4)

CALL OFEN(O J JSFEC, 2, IEFE , 2$)$

TYFE'OFEN IER = Y TER

C.ALI..L FILOT $(0,0,0.0,3)$

ACCEFT'SFECTFUH \# TO FE FLOTTEII?", IF

ACCEFT'Y-AXIS IN INCHES? 'TY

ACCEFT'X-AXIS/LOSO FTS? ' XAX

$X Y=X A X / 1050$

T T.: TY/4096

IF. $T F=I$

KFF::IF*I+I

CALL. RIDBLKK(O,バF, JIAT, 5 , IER)

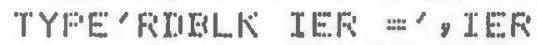

IIO $7 \mathrm{~J}=1,1050$

$X A X \operatorname{Ts}(J)=. J X X Y$

YIAT $(\omega)=$ JIIAT $(J) * T$ T

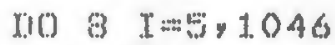

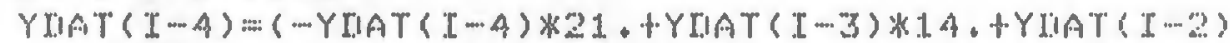

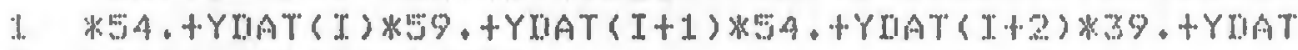

$2 Y$ YIAT $(I+4) * 21.) / 23.1$.

IF $(Y \operatorname{IIAT}(\mathrm{I}-4), \operatorname{L.T}, 0,) \operatorname{YIIAT}(\mathrm{T}-4)=0$.

CONT INUE

$X=X A X I S(1)$

$Y=:$ YMAT (1)

CALL LINEE (XAXIN, YIAT , $1050,0,1)$

$X: 10 \% 0 * X Y$

C,ALL... FLOT $(X, 0,0, \ldots 1)$

(i) 101

C.ALL FESET

STOF

ENM 
Program: GCIRSUM.FR

Purpose: This prograin will signal average any number of infrared spectra.

Method: GCIRSUM.FR sums corresponding spectral points for the specified spectra and finds the average.

Inputs: The user needs to specify the file name and the spectra numbers to be signal averaged.

Output: Signal averaged spectra. 


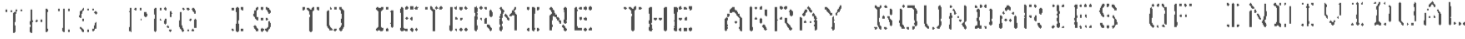

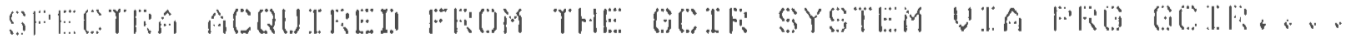

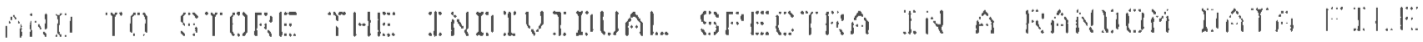

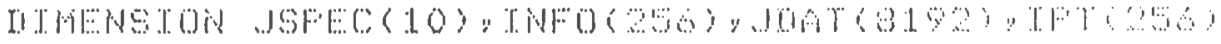

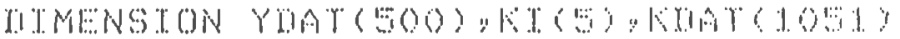

WFITTE(10) ? ?

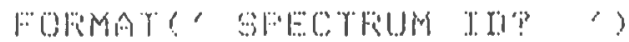

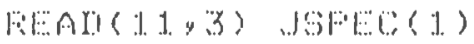

3 FOFMAT $(81.7)$

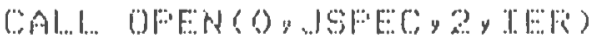

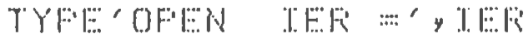

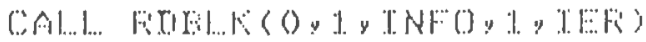

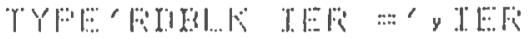

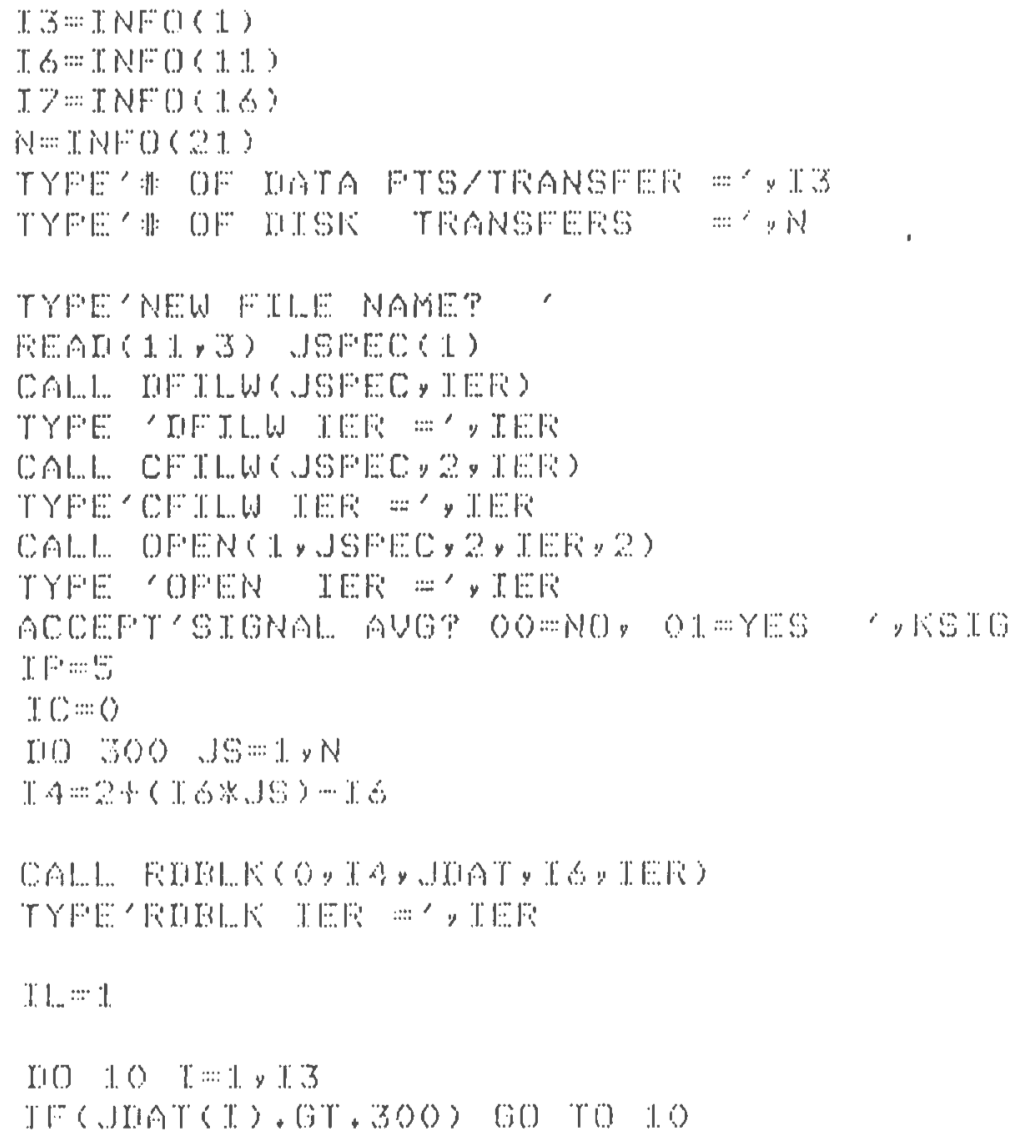


K... T. 1.160

Io $20 \quad 1 \cdots, 1, k$

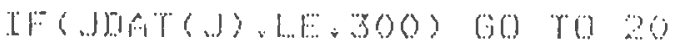

I. $\cdots: .1$

$00 \% 010$

o GONTHE:

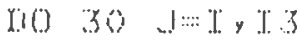

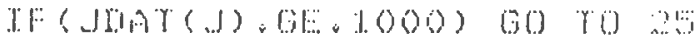

30

CONTTMUE:

(B) TO I. I

$20 \quad$ T.

TFT(TI) $=\ldots .1$

II $\cdots . . .1$

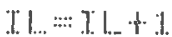

16

conT TMU:

1. 1

cont TNUE

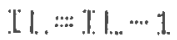

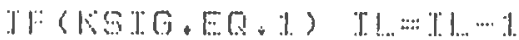

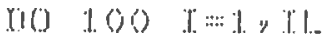

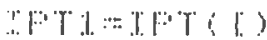

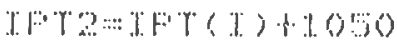

1...: : : : L

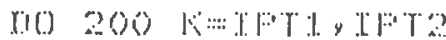

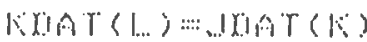

$200 \quad$ I..........1.

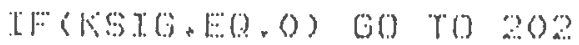

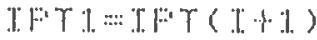

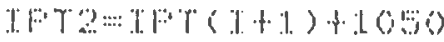

L.. $=:=1$.

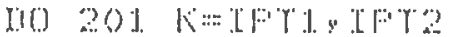

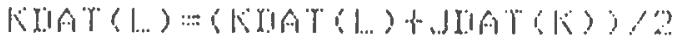

$201 \quad 1 .=1 .+1$

no? Contrinte

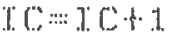

YSUM

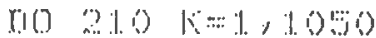

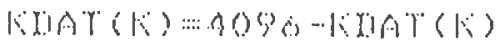

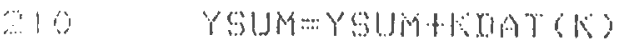

YYAT (TC) Y.:. YSUM

TYF' TC: , TC

$100 \quad$ OONTWHE

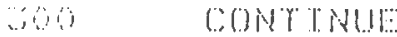


小)

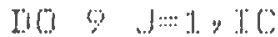

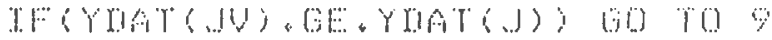

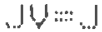

(contringe:

xw:

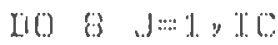

9

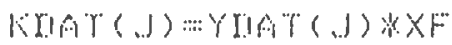

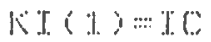

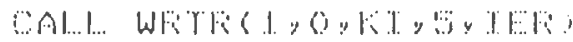

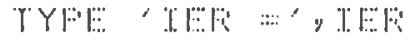

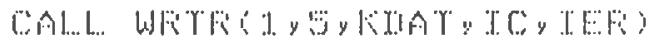

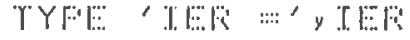

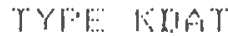

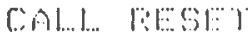

$3 \mathrm{TOF}$

Eisl. 